$8-1-2020$

\title{
Support clubs for children and youth in Haiti living with HIV: A case study
}

Susan Settergren

Robert Philippe

Joanne St. Louis

Nathaniel Segaren

Sylvie Boisson

See next page for additional authors

Follow this and additional works at: https://knowledgecommons.popcouncil.org/departments_sbsr-hiv

Part of the Family, Life Course, and Society Commons, International Public Health Commons, and the Medicine and Health Commons

How does access to this work benefit you? Let us know!

\section{Recommended Citation}

Settergren, Susan, Robert Philippe, Joanne St. Louis, Nathaniel Segaren, Sylvie Boisson, Tessa Lewis, Olbeg Désinor, and Kesner François. 2020. "Support clubs for children and youth in Haiti living with HIV: A case study," Project SOAR Final Report. Washington, DC: Population Council. 


\section{Authors}

Susan Settergren, Robert Philippe, Joanne St. Louis, Nathaniel Segaren, Sylvie Boisson, Tessa Lewis, Olbeg Désinor, and Kesner François 

Haiti Living with HIV: A case study

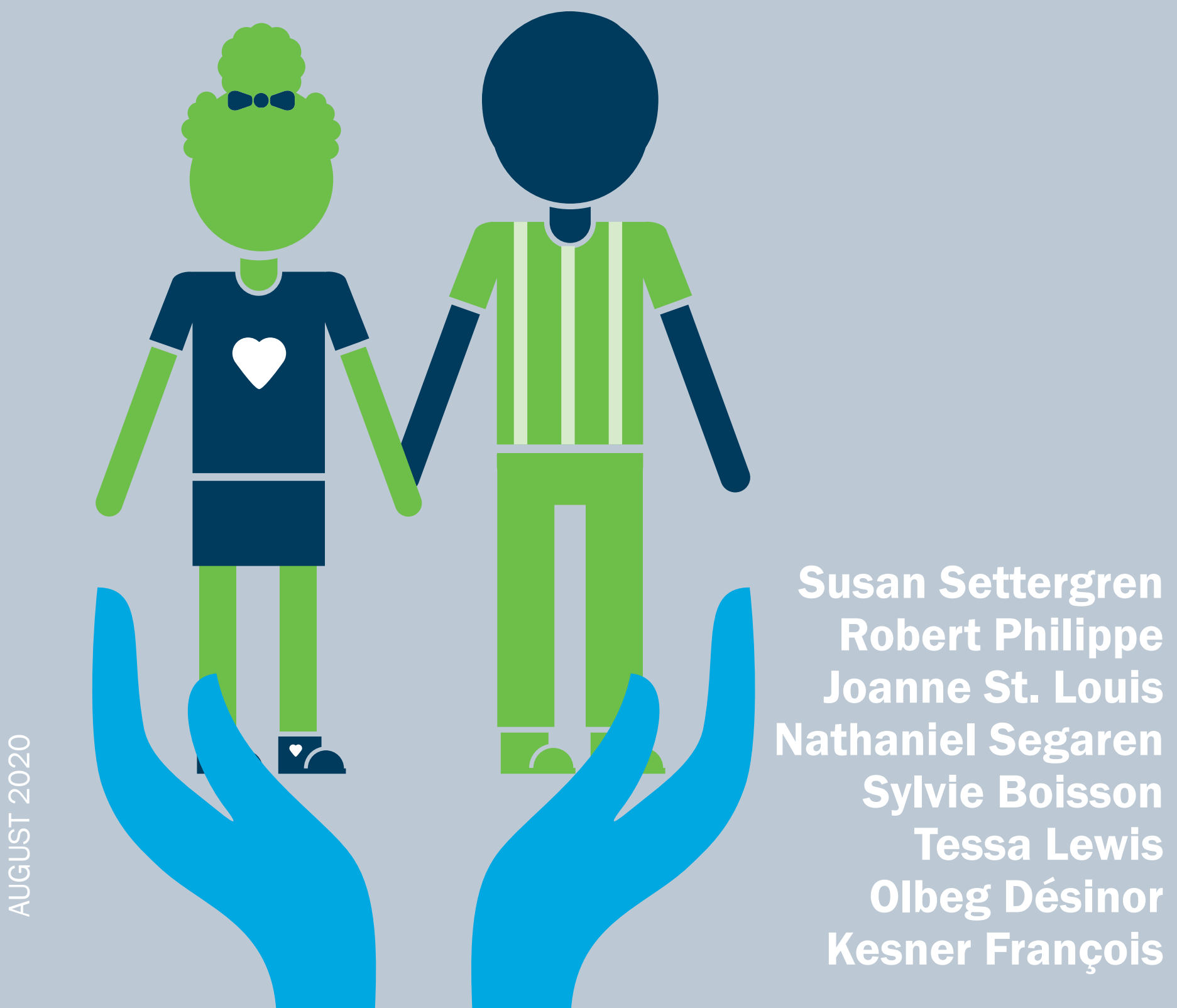

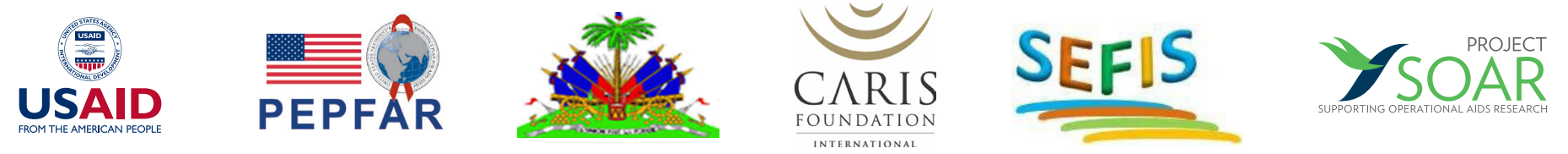


Project SOAR

Population Council

4301 Connecticut Ave, NW, Suite 280

Washington, D.C. 20008 USA

Tel: +12022379400

Fax: +1 2022378410

projsoar.org

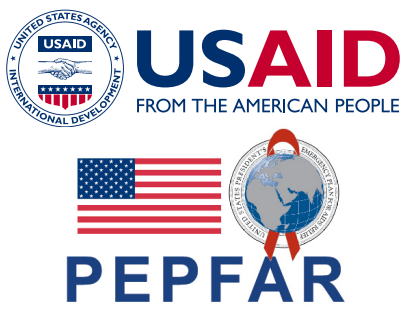

Project SOAR (Cooperative Agreement AID-OAA-A-14-00060) is made possible by the generous support of the American people through the United States President's Emergency Plan for AIDS Relief and the United States Agency for International Development (USAID). The contents of this report are the sole responsibility of Project SOAR and the Population Council and do not necessarily reflect the views of PEPFAR, USAID, or the United States Government.

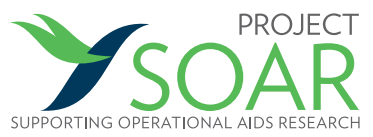

Through operations research, Project SOAR will determine how best to address challenges and gaps that remain in the delivery of HIV and AIDS care and support, treatment, and prevention services. Project SOAR will produce a large, multifaceted body of high-quality evidence to guide the planning and implementation of HIV and AIDS programs and policies. Led by the Population Council, Project SOAR is implemented in collaboration with Avenir Health, Elizabeth Glaser Pediatric AIDS Foundation, Johns Hopkins University, Palladium, and The University of North Carolina.

The Population Council confronts critical health and development issues-from stopping the spread of HIV to improving reproductive health and ensuring that young people lead full and productive lives. Through biomedical, social science and public health research in about 50 countries, the Council works with our partners to deliver solutions that lead to more effective policies, programs, and technologies to improve lives worldwide. Established in 1952 and headquartered in New York, the Council is a nongovernmental, nonprofit organization with an international board of trustees.

Published in August 2020. (C2020 The Population Council, Inc.

Suggested citation: Settergren, Susan, Robert Philippe, Joanne St. Louis, Nathaniel Segaren, Sylvie Boisson, Tessa Lewis, Olbeg Désinor, and Kesner François. 2020. "Support clubs for Haitian children and youth living with HIV: A case study," Project SOAR Final Report. Washington, D.C.: Population Council. 


\section{Support Clubs for Children and Youth in Haiti Living with HIV: a case study}

\section{Susan Settergren}

Palladium

Robert Philippe \& Joanne St. Louis

Société d'Études et de Formation en Information Stratégique

Nathaniel Segaren, Sylvie Boisson, \& Tessa Lewis

Caris Foundation

\section{Olbeg Désinor}

United States Agency for linternational Development/Haiti

\section{Kesner François}

Ministère de la Santé Publique et de la Population, Haiti
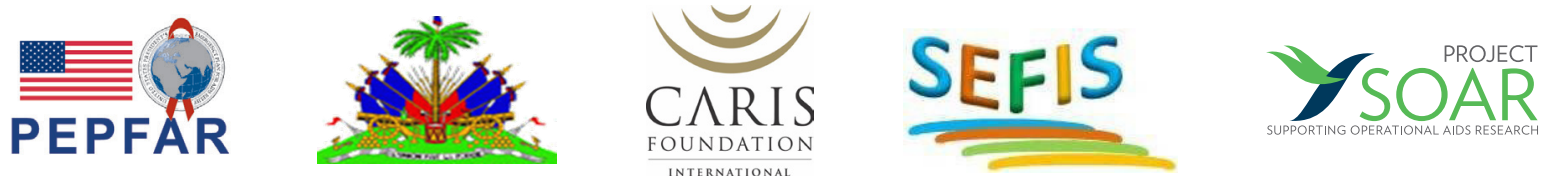


\section{ACKNOWLEDGMENTS}

We thank the United States President's Emergency Plan for AIDS Relief (PEPFAR) for its support of this research and publication. We are most grateful to Alison Chang, Sarah Sandison, and Delivette Castor of the Global Health Bureau/Office of HIV/AIDS, United States Agency for International Development (USAID) for their leadership and guidance on the design and review of this Project SOAR study. The team would like to acknowledge and thank Scott Geibel, Deborah Weiss, Ellen Weiss, Eileen Yam, and Sherry Hutchinson of Population Council for their ongoing management and technical support throughout the project.

This study would not have been possible without the work of many individuals in Haiti. We are grateful to the field data collection team at Société d'Études et de Formation en Information Stratégique (SEFIS)-Cinndy Jean Baptiste Vixamar, Florence Bijou, Gina Joseph, Ismene Catule Bazile, Vanessa J. Pierre, Viker Louis, and Dieudevie Alizé-and to Wedner Pierre and Marc-André Moreau of Unité de Gestion des Projets for their assistance in iSanté data extraction. We are indebted to Anie Charlier Vixamar, Yvon Antoine, Nerline Pierre, and the entire Caris Foundation team for their collaboration throughout implementation of the study.

We offer a special thanks to the many children and youth of the Kids Club program, their caregivers, and program staff who generously shared the stories of their lives and their perspectives on the program through their participation in interviews and focus group discussions. 


\section{TABLE OF CONTENTS}

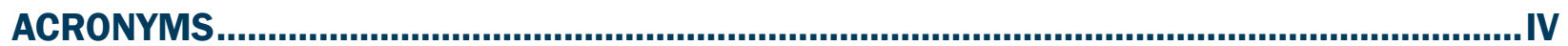

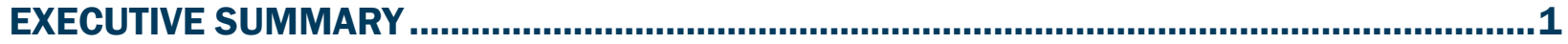

INTRODUCTION........................................................................................................................ 5

ART adherence and retention in care among young people living with HIV ..................................... 5

Bien Et ak Santé Timoun (BEST) Project/Project Impact Youth Kids Clubs Program in Haiti ............ 5

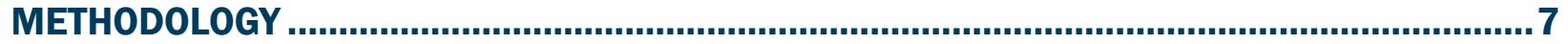

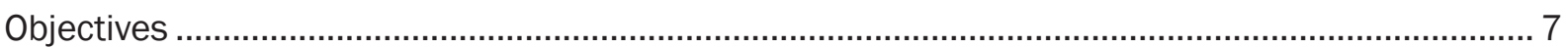

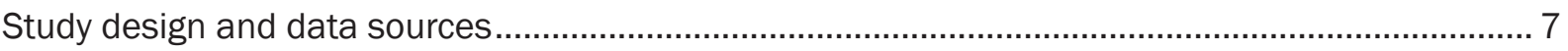

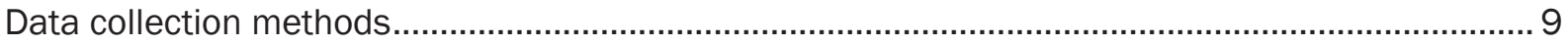

KEY FINDINGS ................................................................................................................... 13

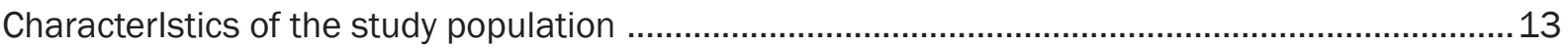

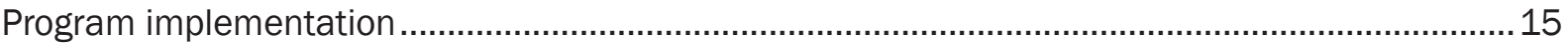

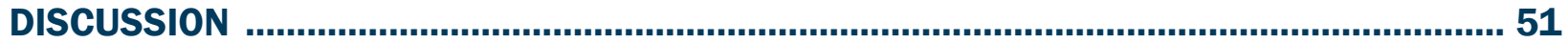

CONCLUSIONS AND RECOMMENDATIONS _.................................................................. 55

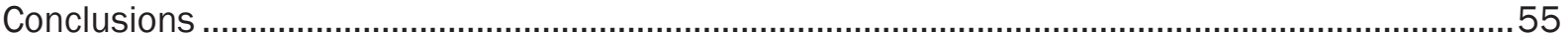

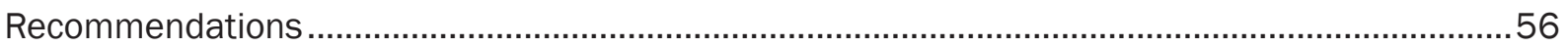

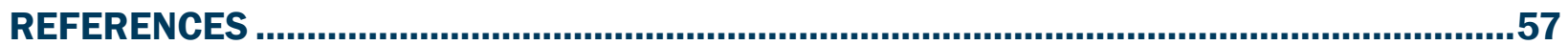

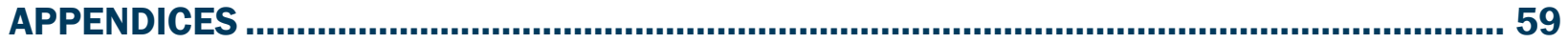

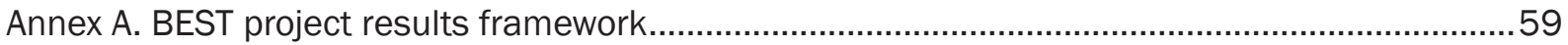

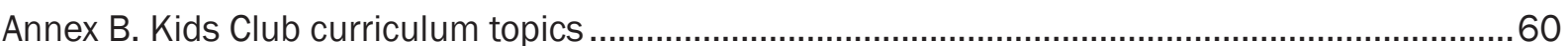




\section{ACRONYMS}

$\begin{array}{ll}\text { ARV } & \text { Antiretroviral } \\ \text { ART } & \text { Antiretroviral therapy } \\ \text { BEST } & \text { Bien Et ak Santé Timoun } \\ \text { CNB } & \text { Comité National de Bioéthique } \\ \text { FGD } & \text { Focus group discussion } \\ \text { GBV } & \text { Gender-based violence } \\ \text { ID } & \text { Identification } \\ \text { IRB } & \text { Institutional review board } \\ \text { WHO } & \text { World Health Organization } \\ \text { M\&E } & \text { Monitoring and evaluation } \\ \text { OVE } & \text { Onited States President's Emergency Plan for AIDS Relief } \\ \text { MSPP } & \text { Ministère de la Santé Publique et de la Population } \\ & \end{array}$




\section{EXECUTIVE SUMMARY}

Although access to antiretroviral therapy (ART) among children and youth living with HIV has increased dramatically in recent years, adherence to medication and viral load suppression have remained challenges. Psychosocial and adherence support groups have shown promise for improving the health and well-being of younger populations, but few have been studied. In Haiti, where an estimated 3,000 children and youth are receiving ART, Caris Foundation, with funding from the United States President's Emergency Plan for AIDS Relief (PEPFAR) through the United States Agency for International Development (USAID), provides hospital-linked psychosocial support groups, known as Kids Clubs, for young people ages nine and older. The clubs are intended to help ensure that HIV-positive children and adolescents stay in contact with health services and serve as a conduit for delivery of other services, including health messages and health products. In 2019, Project SOAR conducted a study to describe the Kids Club program and better understand its impact. Its findings are intended to contribute to the broader evidence base on support groups for young people living with HIV, fill knowledge gaps on how to operationalize and improve this approach, and guide decisions on scale-up and resource allocation in Haiti and globally.

\section{METHODOLOGY}

Project SOAR conducted a retrospective case study of the Kids Club program that Caris Foundation implemented under the USAID project Bien Et ak Santé Timoun (BEST) from 2014 to 2018 and now implements under USAID's Project Impact Youth. It focused on three components: program implementation, outcomes, and costs. Each component involved primary and secondary mixed-methods data that included document review, review of project monitoring data, in-depth interviews, direct observation, focus group discussions (FGDs), and clinical records review. Five club site locations were selected for in-depth study. All data collection occurred from April to September 2019; primary data collection was conducted 4 June-22 August 2019. The protocol was reviewed and approved by the Haiti Comité National de Bioéthique (CNB), Ministère de la Santé Publique et de la Population (MSPP), and Health Media Lab Institutional Review Board (IRB) in the United States.

\section{KEY FINDINGS}

\section{The Kids Club program provided psychosocial support to children and youth receiving ART services at health facilities supported by the BEST project.}

It was implemented through monthly meetings that were tailored to three age groups (9- to 12-year-olds, 13- to 17-year-olds, and 18 years and older) and facilitated by nurse coordinators employed by the BEST project. Meeting content and format included presentation of a health or 
social topic, encouragement to take medication, opportunities for peer interaction, psychosocial counseling, a hot meal, and distribution of hygiene kits.

\section{The Kids Club program was an integral component of the BEST project, which delivered a comprehensive package of medical, behavioral, and structural interventions targeting individual children and youth as well as their support networks.}

Providing more than psychosocial support, the Kids Club program, which was linked to health facilities, served as a nexus of strategies considered essential to improving the lives of highly vulnerable children and youth.

\section{The Kids Club program proved scalable.}

The number of health facilities hosting clubs grew from six to 24 , and enrollment increased nearly tenfold from 2014 to 2018. In 2018, 1,038 children had attended at least one club meeting, representing close to one-third of the estimated number of children in Haiti on ART-with highly active engagement of roughly 20 percent of this population.

\section{The program was implemented with fidelity and quality.}

Interventions were delivered in a consistent manner across the observed sites, and participants and their caregivers described similar program characteristics, experiences, and high levels of satisfaction with the clubs. Children and caregivers frequently commented on and expressed their appreciation for the personalized and compassionate care of the nurse coordinators who implemented the program, remarking on how the coordinators treated the children as their own.

\section{Once enrolled, children and youth tended to stay in the clubs.}

More than three-quarters of those ever enrolled over the five-year period participated for at least a 12-month period. A similar proportion was active in 2018 , and more than half of enrolled children and youth did not miss more than three monthly club meetings that year.

\section{The Kids Club program contributed to participants' learning, behavior change, and well-being.}

Club members, their caregivers, and program implementers described participants learning about personal health, including puberty, the changes their bodies were undergoing, and HIV infection; strategies they have adopted to handle peer pressure and stigma; and overcoming shyness and depression. Importantly, they reported the clubs have helped members keep their clinic appointments.

\section{Program participation was associated with better ART adherence and viral suppression.}

Nearly all study participants reported that the clubs have helped children and youth adhere to their antiretroviral (ARV) medications. Approximately three-quarters of club participants 
reported consistent medication use at their most recent clinic visit. A total of 64 percent of Kids Club members with a recent viral load assessment were virally suppressed. The level of club attendance was associated with ART adherence and viral load suppression.

\section{Commodities and transportation for participants accounted for the majority of Kids Club program costs.}

The estimated cost of delivering the program in 2018 was US $\$ 113,521$, with a per capita cost ranging from US $\$ 109$ to US\$162, and an average cost per meeting of US\$172. Given the integrated nature of the service delivery package through which it was delivered, program components specific to the Kids Club program, such as meals provided at club meetings, transportation allowance for meeting attendance, and provision of hygiene kits, accounted for more than 80 percent of total costs.

\section{CONCLUSION AND RECOMMENDATIONS}

The Kids Club program implemented by Caris Foundation under the BEST project from 20142018 was found to be an essential component of a comprehensive package of services delivered at scale to children and youth living with HIV in Haiti. Children and youth who participated in the program were found to have better HIV clinical outcomes compared to national estimates and other recent studies. They and their caregivers also reported many other benefits of club participation, including improved health and psychosocial well-being. Importantly, children and youth attributed changes in their acceptance of living with HIV as well renewed hope for their futures to the clubs. The study's in-depth look at implementation of the Kids Club program suggested that much of its success can be attributed to its close linkages with other mutually reinforcing intervention components as part of a comprehensive package-and that the clubs served to strengthen those linkages. As a facility-based model, it offered an alternative approach to the more commonly implemented community-based psychosocial support groups and could be explored as a supplement to case management. Finally, the program was observed to be performing well using available tools and processes, such as its curriculum, training and supportive supervision, and participant monitoring methods, which could be adapted for scale-up in other settings within and outside of Haiti.

Based on the study findings and conclusion, we offer the following recommendations, directed to two audiences. For Caris Foundation, as it continues to implement the Kids Club program under Project Impact Youth: (1) continue implementation while seeking ongoing operational improvements, including those offered by study participants; (2) re-examine and fine tune progression protocols and their implementation to ensure that HIV curriculum topics are delivered to children as they learn their HIV status; (3) take a closer look at the variation in club participant outcomes across sites, identify factors contributing to the differences, implement strategies to scale up best practices and target resources to address gaps, and continuously monitor differences and trends; and (4) continue to find ways to promote club meeting attendance to ensure optimal benefits from program participation.

For national program leaders and PEPFAR and other global decisionmakers: (1) share study findings and foster dialogue on the facility-based model of the Caris Foundation Kids Club 
program vis-à-vis other psychosocial support models for children and youth living with HIV, and promote exchange of tools and learning; (2) continue to motivate and test innovative solutions that support children and youth living with HIV not only to adhere to their medication and maintain viral suppression, but also transition to adulthood and become productive members of society; and (3) support locally led, sustainable psychosocial support approaches that engage the leadership of youth living with HIV. 


\section{INTRODUCTION}

\section{ART ADHERENCE AND RETENTION IN CARE AMONG YOUNG PEOPLE LIVING WITH HIV}

Worldwide, much progress has been made in recent years to increase access to antiretroviral therapy (ART) for the estimated 1.8 million young people living with HIV. Nearly twice as many children were receiving treatment in 2017 compared to 2010 (UNICEF 2018). However, ART adherence and viral load suppression remain a challenge (Teasdale et al. 2018; Davies et al. 2011; lacob et al. 2017; Glass et al. 2015; Teasdale et al. 2013). ART adherence among adolescents has been found to be particularly challenging for a number of reasons (Fetzer et al. 2011; Vaz et al. 2010; Castro et al. 2015; White et al. 2008). Adolescence often is a time when individuals learn their HIV status and typically when they are transitioned from pediatric to adult medical care, which brings increased expectations of responsibility. At the same time, it is also a life stage when individuals undergo major cognitive, emotional, and social changes, which can compound the challenges of adherence and retention in care. For example, adolescents' lack of routine, nondisclosure, and mental health, as well as the stigma surrounding HIV, all have been found to be negatively associated with ART adherence (Fields et al. 2017; Smith Fawzi et al. 2016).

Little scientific evidence is available regarding strategies to improve adherence among adolescents in low- to middle-income countries (Ridgeway et al. 2018; Shaw and Amico 2016; Bain-Brickley et al. 2011). However, adherence support groups, which have been implemented in a variety of settings, have shown promise (Murray et al. 2017; PEPFAR Solutions Platform 2018; WHO 2016). World Health Organization (WHO) guidelines on the use of antiretroviral drugs for treating and preventing HIV infection include support groups among the recommended approaches for strengthening retention in care and ART adherence among young people, citing the balance of potential benefit to harm and their acceptability to people living with HIV as the rationales for the recommendation. WHO also notes the importance of tailoring approaches to local contexts and the need for stronger evidence on the cost-effectiveness of intervention packages (WHO 2016).

\section{BIEN ET AK SANTÉ TIMOUN (BEST) PROJECT/PROJECT IMPACT YOUTH KIDS CLUBS PROGRAM IN HAITI}

In Haiti, an estimated 6,100 children ages 10-29 years were living with HIV in 2017, and about half of them were receiving ART (UNICEF 2018). From 2014 to 2018, Caris Foundation, through the Bien Et ak Santé Timoun (BEST) project funded by the United States President's Emergency Plan for AIDS Relief (PEPFAR) through the United States Agency for International Development (USAID), provided support to HIV-positive children at more than 130 hospitals throughout Haiti's 10 departments. The overall objective of the project was to help children in Haiti affected and infected by HIV/AIDS grow into healthy, educated young adults. Caris Foundation is continuing this 
work under USAID's Project Impact Youth, launched in 2019. Hospital-linked psychosocial support groups for young people living with HIV, known as Kids Clubs, were a core component of the BEST project and are continuing under Project Impact Youth. The clubs, tailored to three age groups (9- to 12-year-olds, 13- to 17-year-olds, and 18 years and older), are intended to help ensure that HIV-positive children and adolescents stay in contact with health services and serve as a conduit for delivery of other services, including health messages and products. The Kids Club program aligns with the priorities of the Government of Haiti to promote psychosocial care and integration of people living with HIV/AIDS and affected families into social and public assistance programs supported by the Haitian government and its national and international partners (Programme National de Lutte contre les IST/VIH/Sida 2016). The program also contributes directly to the Haitian government and PEPFAR goals to control the HIV epidemic within the next several years (PEPFAR 2018).

An underlying hypothesis of the Kids Club program is that participation in the clubs contributes to retention in care and improved treatment outcomes. Anecdotal evidence over the years suggested that the program was well received among participants, their parents and caregivers, and program implementers, and has contributed to better health and well-being of participants. The study presented in this report was undertaken to provide an in-depth description of its implementation and impact. Findings are intended to contribute to the broader evidence base on support groups for young people living with HIV, fill knowledge gaps on how to operationalize and improve this approach, and help guide decisions on scale-up and resource allocation in Haiti and globally. 


\section{METHODOLOGY}

\section{OBJECTIVES}

The overall aim of the study was to describe the BEST/Project Impact Youth Kids Club program and its impact on participants to advance knowledge about programs for young people living with HIV/AIDS that aim to promote ART adherence, retention in care, and viral suppression. The study objectives were defined by three primary research questions:

- How does the Kids Club program operate? What is its history? What are its interventions? How are they implemented? To date, what have been the success factors and challenges in implementation? How can the program be strengthened?

- What effect has the Kids Club program had on participants? Who participates, how often, and for how long? What effect has club participation had on participants' lives and the lives of their families? Is club participation associated with better treatment outcomes, including ART adherence, retention in care, and viral load suppression? What do participants and their parents or caregivers value about the clubs?

- What is the cost of the program? What are the resource requirements and costs of operation? What are the cost drivers? What are the unit costs?

\section{STUDY DESIGN AND DATA SOURCES}

The study was designed as a retrospective case study of the Kids Club program; it focused on three components: program implementation, outcomes, and costs. Each component involved primary and secondary mixed-methods data that included document review, review of project monitoring data, in-depth interviews, direct observation, focus group discussions (FGDs), and clinical records review. Study topics and data sources are presented in Table 1.

The study team selected five club site locations and clubs (Table 2) for in-depth study. The team purposefully selected sites based on club enrollment, types of clubs offered (i.e., defined by age groups), geographic diversity within the country, and accessibility. ${ }^{1}$

${ }^{1}$ Initial plans to include a location in Centre department had to be abandoned due to insecurity within that area at the time of data collection. 


\section{Topic \\ Data source(s)}

\section{Program implementation}

Characteristics of club enrollees. Demographics, club type, clinic enrollment

History. Objectives/purpose, motivation for the clubs, program/club start-up and roll out, implementation timeline, evolution/changes over time

Intervention design and implementation. Program/ service delivery model, theory of change, curricula, tools, eligibility requirements, enrollment process, transition/ graduation protocol, club meeting schedules

Management and operations. Organizational structure, management, staffing, monitoring and evaluation, linkages with other services and service providers

Club attendance. Historical trends of enrollment and attendance, factors associated with attendance

Assessment of program implementation. Successes, challenges, and recommendations for improving program implementation

\section{Program outcomes}

Clinical indicators. ART adherence, viral load suppression

Reported outcomes of Kids Club participation. Child health, psychosocial well-being, retention in clinical care, ART adherence, other benefits

\section{Program costs}

Resource requirements. Labor/personnel, materials and supplies, training, facility and operations

Capital and recurrent costs. Annual total and per capita costs, cost drivers
Project monitoring data, clinical records, club observation

Document review, interviews with program staff

Document review, interviews with program staff, observation of clubs

Document review, interviews with program staff

Project monitoring data, interviews with program staff, FGDs with club participants, FGDs with caregivers

Interviews with program staff, observation of clubs, FGDs with club participants, FGDs with caregivers

Clinic records

Interviews with program staff, FGDs with participants, FGDs with caregivers

Document review, interviews with program staff

Document review, interviews with program staff 
Table 2. Sites selected for in-depth study

\begin{tabular}{|c|c|c|c|}
\hline Site & Department & $\begin{array}{l}\text { Club types } \\
\text { observed and } \\
\text { FGDs conducted }\end{array}$ & $\begin{array}{c}\text { Number of } \\
\text { children/youth } \\
\text { who attended at } \\
\text { least one club } \\
\text { meeting in } 2018\end{array}$ \\
\hline Grace Children's Hospital & Ouest & 13- to 17-year-old & 23 \\
\hline Hôpital Bernard Mevs & Ouest & 9- to 12-year-old & 14 \\
\hline $\begin{array}{l}\text { Hôpital Saint Damien Nos Petits Freres et } \\
\text { Soeurs }^{1}\end{array}$ & Ouest & $\begin{array}{l}\text { 9- to 12-year-old } \\
\text { 13- to } 17 \text {-year-old }\end{array}$ & $\begin{array}{r}112 \\
71\end{array}$ \\
\hline Hôpital Immaculée Conception des Cayes & Sud & $\begin{array}{c}\text { 9- to 12-year-old } \\
\text { 13- to 17-year-old } \\
\text { 18-year-old + }\end{array}$ & $\begin{array}{l}76 \\
30 \\
26\end{array}$ \\
\hline Hôpital Sacré Coeur de Milot & Nord & $\begin{array}{c}\text { 9- to 12-year-old } \\
\text { 13- to 17-year-old } \\
\text { 18-year-old + }\end{array}$ & $\begin{array}{l}20 \\
20 \\
11\end{array}$ \\
\hline
\end{tabular}

${ }^{1}$ Due to the large number of enrolled children, clubs at this site are defined by narrower age groups. In the study, we collected data at the 11-year-old and 15- to 17-year-old clubs.

\section{DATA COLLECTION METHODS}

\section{Document review}

The study team reviewed all documents regarding the Kids Club Program that Caris Foundation program managers made available. These materials included a summary description of the Kids Club program, excerpts from 2014 to 2018 BEST Project annual performance reports to USAID that described program scale-up, and the schedule of educational topics and excerpts from the Kids Club curriculum.

\section{Project monitoring data}

For the purposes of the study, Caris Foundation extracted data from its project monitoring database on all children enrolled in the Kids Club program from 2014 through 2018. A Microsoft Excel file was created that contained 1,330 records (one for each enrolled child). Variables included sex of the child, date of birth, club name and location, type of club, date of first club meeting, date of last club meeting, number of club meetings attended, and attendance status in 2018. The file also included the patient identifications (IDs) of club enrollees, which were used to extract their clinical records. 


\section{Interviews with program staff}

The study team conducted face-to-face, semi-structured interviews with Caris Foundation staff who had historic knowledge of and/or currently manage and implement the Kids Club program. Fifteen staff were interviewed during the period 24 June-22 August 2019, including the Country Director and Deputy Country Director of Caris Foundation in Haiti; the Project Director, Education Director, and Monitoring and Evaluation Director of Project Impact Youth; and 10 nurse coordinators who implement the Kids Club Program at the five club site locations selected for in-depth study. Management staff interviews were conducted one on one, whereas nurse coordinators were interviewed one on one or in groups of two, three, or four, according to staffing at the sites. Interviews were conducted in English, French, or Haitian Creole, depending on the preference of the interviewee. Upon receipt of consent, interviews were audio recorded. Written transcripts of the recordings were prepared in the language of the interview and then translated into English.

\section{Cost data}

Itemized cost data were collected through a written questionnaire that detailed staffing, capital, and recurrent program costs. It was completed by Caris Foundation management staff.

\section{Observation of Kids Clubs}

Trained observers documented club meetings through direct, passive observation of routinely scheduled club meetings at the in-depth study sites. They recorded observations through an electronic checklist and in narrative format captured on a tablet. They observed 10 clubs during the period 4 June-26 July 2019: four 9- to 12-year-old clubs, four 13- to 17 -year-old clubs, and two 18-year-old + clubs.

\section{Focus group discussions with club members and parents/caregivers}

FGDs were conducted separately for children and their parents/caregivers for the 10 clubs selected for observation ${ }^{2}$ and held either the day before or the day after the observation. For each club, 12 members (and their caregivers) were randomly selected and invited to participate from among members who actively participated in the Kids Club program during the period JanuaryDecember 2018. ${ }^{3}$ Personal invitations were extended a week in advance of the scheduled FGDs. Informed consent was administered to the caregivers for themselves and their children, and for club members ages 18 and older; informed assent was administered to club members under age 18. Groups ranged in size from 7 to 12 club members and 7 to 10 parents/caregivers, and in length from 60 to 90 minutes. All FGDs took place at the location of the club meetings. Trained facilitators led the discussions in Haitian Creole, using guides tailored to the club's age group. A note taker took summary notes, and the discussions were audio recorded. Creole transcripts were prepared from the recording and then translated into English.

${ }^{2}$ Parent/caregiver FGDs were conducted only for the 9- to 12-year-old and 13- to 17-year-old clubs, for a total of eight parent/ caregiver FGDs.

${ }^{3}$ Caris Foundation provided the list of active club members. Active participation was defined as having missed three or fewer club meetings during the calendar year. 


\section{Clinic records}

The study team obtained clinic record data from the Ministère de la Santé Publique et de la Population (MSPP) iSanté national electronic medical record central server database, managed by Unité de Gestion des Projets. A consultant familiar with the database extracted the data based on the listing of patient IDs for the 1,330 children ever enrolled in the Kids Club program and data specifications provided by the study team. No personally identifiable information was obtained. Data were extracted from six clinic forms: patient registration, initial visit, follow-up visit, medication, adherence, and laboratory. Data were obtained from all forms that captured multiple visits for the three-year period 1 September 2016-31 August 2019. Patient registration and initial visit forms were available for approximately three-quarters of all ever-enrolled children. Complete data (i.e., at least one record for all six forms) were available for 69 percent of Kids Club enrollees (Table 3).

\section{Table 3 Availability of clinic record data extracted from the iSanté central server}

\begin{tabular}{|c|c|}
\hline Data form & $\begin{array}{c}\text { Number }(\%) \text { of cases with extracted clinic data from among } \\
\text { the } 1,330 \text { children ever enrolled in a Kids Club }\end{array}$ \\
\hline Patient registration & $1,045(78.6)$ \\
\hline Initial/intake visit & $1,026(77.1)$ \\
\hline Follow-up visits (at least one form ${ }^{1}$ ) & $986(74.1)$ \\
\hline Medication (at least one form ${ }^{1}$ ) & $992(74.6)$ \\
\hline Adherence (at least one form ${ }^{1}$ ) & $973(73.2)$ \\
\hline Laboratory (at least one form ${ }^{1}$ ) & $960(72.2)$ \\
\hline All forms & $911(68.5)$ \\
\hline
\end{tabular}

${ }^{1}$ For the period 1 September 2016-31 August 2019.

\section{Ethical review}

The protocol was reviewed by the Haiti Comité National de Bioéthique (CNB), MSPP, and Health Media Lab Institutional Review Board (IRB) in the United States. CNB approval for all components except the secondary analysis of clinical data was granted on 16 May 2019; approval of the final component was given on 4 September 2019, following receipt of MSPP approval to access the data for the study. Health Media Lab approval was received on 24 April 2019, and the Population Council IRB granted a deferral to the Health Media Lab IRB on 29 July 2019. 


\section{Data analysis}

Qualitative data obtained from the interviews, club observations, and FGDs were coded by analysis topic using Atlas.ti 8 . Themes within topics were summarized first by data source and then merged across data sources. Quotations supporting the themes were then extracted from the transcripts. To maintain anonymity of the staff interviewed, codes were randomly assigned when reporting attribution; that is, program managers were coded as A-E and nurse coordinator interviews were designated as Groups A-D.

Cost data were tabulated and analyzed using MS Excel. Project monitoring and clinical data were analyzed using IBM SPSS Statistics version 25. Consistency and range checks were performed separately on each data source, and key fields-date of birth, sex, and club meeting/clinic visit dates-were cross-checked in the merger of Kids Club and clinic records. Unless otherwise noted in the findings, all available data were used in analysis of the clinical data. Chi-square and Fisher's Exact tests were used to test differences among categorical variables. 


\section{KEY FINDINGS}

\section{CHARACTERISTICS OF THE STUDY POPULATION}

\section{In-depth study sites (primary data)}

A total of 162 children (female and male) were observed in the 10 clubs at the in-depth study sites. In total, 96 children (54 female and 42 male) participated in the 10 FGDs. Some, but not all, children who participated in an FGD were also observed in a club. Most of the 69 caregivers who participated in the eight FGDs were female. Many caregivers were not the biological parents of the children in the clubs, but rather sisters, grandmothers, aunts, and others who were caring for the children, often under challenging circumstances. ${ }^{4}$

I am in charge of 11 children. My brother died and left 11 children, I have eight living with me; three have a mother and eight do not have a mother. [I have] many things to say; when someone leaves eight children for you to take care of it is not a piece of cake.

-Caregiver of child in 13- to 17-year-old club, Hôpital Sacré Coeur de Milot

It's me who always gives the drugs to the child. I give them to her. Her mom is about to die because she does not want to drink the drugs...she doesn't care.

-Caregiver of child in 9- to 12-year-old club, Hôpital Immaculée Conception des Cayes

\section{Kids Club participants (secondary data)}

Table 4 (next page) presents characteristics for the club participants for those ever enrolled in a club and for the sub-population for whom some clinical data could be retrieved (i.e., a patient intake form existed in the central iSanté database). The largest number of children enrolled in a Kids Club through December 2018 were located in the Ouest department of the country and the smallest number in Nord-Est-581 and 24, respectively. The rate of enrollment was highest during the 2015-2017 period-about three-quarters of club members joined a club at that time. Most children (81 percent) had been seen at an HIV clinic before the start of the BEST Kids Club program in 2014. Female children comprised a slightly larger percentage (53 percent) of children ever enrolled. About one-third of enrollees (36 percent) began attending a club at ages 8-12, while 44 percent were ages 13-17 and 21 percent were ages 18-29. As of December 2018, 43 percent last attended a 9- to 12-year-old club, while 42 percent and 14 percent last attended a

${ }^{4}$ This observation is consistent with clinic registration data showing that for 37\% (304/813) of the children, someone other than the child's biological mother or father was responsible for making medical decisions on behalf of the child. 
Table 4 Characteristics of Kids Club participants

\begin{tabular}{|c|c|c|}
\hline Club participant characteristics & $\begin{array}{c}\text { Ever enrolled } \\
\begin{array}{c}(\mathrm{N}=1,330) \\
\%(\mathrm{n})\end{array}\end{array}$ & 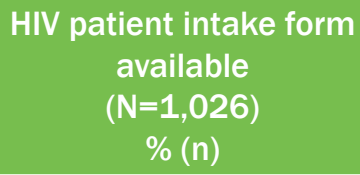 \\
\hline \multicolumn{3}{|l|}{ Department } \\
\hline Artibonite & $3(34)$ & $0.6(6)$ \\
\hline Centre & $3(40)$ & $4(38)$ \\
\hline Grand'Anse & $4(58)$ & $5(54)$ \\
\hline Nippes & $4(49)$ & $5(49)$ \\
\hline Nord & $15(203)$ & $18(186)$ \\
\hline Nord-Est & $2(24)$ & $1(13)$ \\
\hline Nord-Ouest & $8(105)$ & $6(65)$ \\
\hline Ouest & $44(581)$ & $40(405)$ \\
\hline Sud & 14 (191) & $16(167)$ \\
\hline Sud-Est & $3(45)$ & $4(43)$ \\
\hline \multicolumn{3}{|l|}{ Year of club enrollment } \\
\hline 2014 & $11(148)$ & $11(114)$ \\
\hline 2015 & $32(422)$ & $32(323)$ \\
\hline 2016 & $25(336)$ & $28(289)$ \\
\hline 2017 & $21(273)$ & 19 (198) \\
\hline 2018 & $11(151)$ & $10(102)$ \\
\hline \multicolumn{3}{|c|}{ Year of initial visit at a health facility } \\
\hline Before 2014 & - & 81 (831) \\
\hline 2014 & - & $6(56)$ \\
\hline 2015 & - & $6(65)$ \\
\hline 2016 & - & $5(46)$ \\
\hline 2017 & - & $2(22)$ \\
\hline 2018 & - & $0.5(6)$ \\
\hline \multicolumn{3}{|l|}{ Sex } \\
\hline Female & $53(703)$ & $52(542)$ \\
\hline Male & $47(627)$ & $48(503)$ \\
\hline \multicolumn{3}{|l|}{ Age at club enrollment ${ }^{1}$} \\
\hline $8-12$ years & $36(472)$ & 38 (389) \\
\hline 13-17 years & $44(579)$ & $43(436)$ \\
\hline $18-29$ years & 21 (279) & $20(201)$ \\
\hline \multicolumn{3}{|l|}{ Last club type attended } \\
\hline 9- to 12-year-old & $43(575)$ & 46 (471) \\
\hline 13- to 17-year-old & $42(563)$ & $41(418)$ \\
\hline 18-year-old + & $14(192)$ & $13(137)$ \\
\hline
\end{tabular}

Source: Caris Foundation project monitoring database and clinic records.

${ }^{1}$ Calculated based on date of birth and date of first club meeting. 
13- to 17-year-old and 18 years and up club, respectively, suggesting that some enrollees had not moved to a new club type as they aged. One program manager explained as follows:

We have quite a few children who are developmentally delayed and they're not ready to move up. So that's why in some cases we have older children in the younger aged clubs.

\section{_-Program manager E, Caris Foundation}

Characteristics among the sub-population with available clinical data were similar to those for all ever-enrolled children.

\section{PROGRAM IMPLEMENTATION}

\section{History}

Caris Foundation reportedly recognized the need for a support network for children living with HIV as far back as 2010-support that could complement their clinical care. Before implementation of the Kids Club program under the BEST project, support clubs were piloted at two hospitals: Hôpital de I'Université d'Etat d'Haïti et Maternité Isaïe Jeanty. They were loosely based on other clubs for children living with HIV but designed specifically for Haiti. Positive outcomes of the program were observed, including better retention in clinical care.

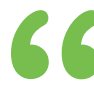

It was an idea that we had just through our work. We encountered a large number of children and teenagers living with HIV and they didn't have any kind of support network, so that's why the idea came to us to form a club ... a confidential environment to be together and speak openly without worrying about confidentiality issues ... We knew of other models happening in countries in Africa, but really our inspiration came just from working with the children in the hospitals where we were working.

-Program manager E, Caris Foundation

66 [Early implementation] showed that the patients came back. Participation rate was high at the clubs, [so] we were able to monitor their medical appointments. The kids liked it and the care providers at the hospital liked it as well ... because the kids came. They felt ... it encouraged them to come back for their appointments. They planned appointments for the date of the club ... so they knew the kids would come in.

-Program manager D, Caris Foundation

Based on this success, the program was expanded under the BEST project and scaled up from four hospitals in 2014 to 24 hospitals in 2018 . Site eligibility was based on a minimum of five to seven eligible children who were patients at the site (i.e., ages 9-24 and diagnosed with HIV) and agreement of site leadership to initiate the activity. During the five-year period, club enrollment increased nearly tenfold, from 148 to 1,330. Overall, the highest rates of growth in enrollment occurred in 2015 and 2016, and enrollment growth was greatest among the 9- to 12-year-old 
clubs compared to the 13- to 17 -year-old and 18 years and up clubs. Details are presented in Table 5.

Table 5 Cumulative number of hospital club sites and children enrolled each year

\begin{tabular}{|l|c|ccc|c|}
\hline $\begin{array}{l}\text { Year of enrollment } \\
\text { (Jan-Dec) }\end{array}$ & $\begin{array}{c}\text { Number of } \\
\text { hospital sites }\end{array}$ & $\begin{array}{c}\text { Last club type attended } \\
\text { 9- to 12- } \\
\text { year-old }\end{array}$ & $\begin{array}{c}\text { 13- to } \\
\text { 17-year-old }\end{array}$ & 18-year-old + & All clubs \\
\hline 2014 & 4 & 52 & 72 & 24 & 148 \\
2015 & 14 & 145 & 301 & 124 & 570 \\
2016 & 20 & 304 & 436 & 166 & 906 \\
2017 & 23 & 476 & 523 & 180 & 1,179 \\
2018 & 24 & 575 & 563 & 192 & 1,330 \\
\hline
\end{tabular}

Source: BEST project monitoring database.

Except for program expansion over the BEST five-year period (and in 2019 under Project Impact Youth), the Kids Club program reportedly underwent little change since being established, except regarding curriculum updates (see below).

2 There has been little change; on the whole, it is the same [program] logic, [supporting] vulnerable children, HIV-positive children.

-Program manager B, Caris Foundation

\section{Program objectives and design}

The Kids Club program was motivated by and designed to address a number of factors affecting children living with HIV. Although no theory of change was documented, expected outcomes were specified in project documents. Program managers cited multiple expected outcomes of the program, ranging from improved ART adherence, retention in care, and viral load suppression to better knowledge of HIV and other health issues to stronger social networks and greater individual self-esteem.

We wanted to have a place that adolescents living with HIV could be together as a

way to improve adherence ... to the clinical visits, to have an understanding of HIV, to have friendship and psychosocial support with their peers, and ultimately to lead to disclosure of their status ... to help with [ART] adherence ... [and so] we can monitor the children's health ... If [the clubs] help viral suppression, that would be the best.

-Program manager D, Caris Foundation 


\section{Kids Club program expected outcomes}

1. Increase knowledge of HIV-positive beneficiaries about HIV (causality, transmission, care, prevention).

2. Increase positive behavior and personal hygiene of HIV-positive beneficiaries.

3. Increase adherence-medications and periodic visits to hospitals-so that each participant eventually has an undetectable viral load.

4. Provide a safe and confidential place for young people to share their experiences and feelings with confidence.
5. Improve the mental health of HIV-positive beneficiaries, decrease the rate of depression, and increase self-esteem.

6. Improve personal behavior and reduce unsafe sex among HIV-positive adolescents.

7. Improve the quality of life of HIV-positive adolescents.

Source: Description et rôle des CLUBS d'Enfants, Caris Foundation

The primary goal is really to improve their adherence, adherence to treatment and medical visits, and really that's from a medical point of view. But also, from a wellness point of view, [to improve] self-esteem-so that the person can blossom.

-Program manager A, Caris Foundation

66 We hope that the children in the Kids Club have a strong awareness of different health topics, especially when it comes to sexual relationships, knowing how to protect themselves and knowing when to say no to something they're not comfortable with, and knowing what their rights are....

-Program manager E, Caris Foundation

66 We wanted it to not only be educational, [but also] a fun place for them to be... We wanted them to have meals so they could eat all together like in a family environment. We wanted it to be more than just another school session, but more like of a meeting place for friends as well.

-Program manager E, Caris Foundation

\section{Implementation strategy}

The Kids Club program was just one component of a comprehensive program of services delivered by BEST for early infant diagnosis and treatment of HIV.

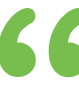

When a child is HIV-positive [at a site we support], we offer her/him different services. The club is one of the services. [The others include] tracking, i.e., helping to ensure that children are placed on ARVs, that they have their viral load [tested]. We do home visits or follow-ups for the children who are in the clubs. We offer school support for all positive patients at the sites with whom we collaborate, so the children in the clubs 
are part of that ... we pay school fees to a certain amount. We also distribute chlorine and albendazole twice a year. We make sure that siblings of the children who are in the clubs are tested for HIV. We also have an economic strengthening program for caregivers ... we invite the parents to become part of the solidarity credit union with savings groups and credit. We have a gardening program in some departments. There is also a referral system; if we identify a child with a problem, for example, a victim of sexual or physical violence or with extreme psychosocial problems, we can refer the child. We have a department of psychologists and social workers.

\section{-Program manager A,} Caris Foundation

Caregivers typically viewed the club program as synonymous with this constellation of services-most important, home visits and payment of school fees.

\section{BEST project program of services}

- Tracking of HIV-positive pregnant women

- Testing of infants born to HIV-positive mothers

- Tracking of HIV-positive children

- Educational support for HIV-positive children

- Kids Clubs

- Malnutrition screening

- Assistance to parents for status disclosure to adolescents

- Psychosocial support groups for HIVpositive pregnant women

- Household economic strengthening programs

- Health and human rights community messaging

Source: BEST Results Framework (see Annex A)

When the child goes to the club, they can give him/her a kit, they give him/her a hot meal, some people were happy with only that. But Caris is not happy with that, they consider the health of the child. They also have agents who come home to talk to you. If there is a serious problem, they send a psychologist to talk to you.

-Caregiver of child in 13- to 17-year-old club, Hôpital Saint Damien Nos Petits Freres et Soeurs

The nurses always visit me to verify if the child takes the medications, how they take them. They come to tell me how to take care of the child. Last time, when the child was not feeling well and couldn't come to the club, they visited him at home.

-Caregiver of child in 9- to 12-year-old club, Hôpital Sacré Coeur de Milot

Helping to pay the children's school tuition is one of the greatest advantages [of the program]

-Caregiver of child in 13- to 17-year-old club, Hôpital Sacré Coeur de Milot 


\section{Organizational structure and management}

The Kids Club program was administered from the six BEST offices in Port-au-Prince (headquarters), Jérémie, Cap Haïtien, Cayes, Gonaives, and Bombardopolis under the direct management of the education manager at headquarters. Key staff direct roles and responsibilities are provided in Table 6 . All staff are paid employees; Caris Foundation reports a staff retention rate of close to 100 percent under BEST.

\section{Table 6 Kids Club program staffing}

\begin{tabular}{|c|c|}
\hline Staff & Roles and responsibilities \\
\hline Education manager & $\begin{array}{l}\text { Overall management of the Kids Club program, curriculum development } \\
\text { and updates, training and supportive supervision of Nurse Coordinators } \\
\text { on the education component of the clubs }\end{array}$ \\
\hline Deputy country director & Quality control of club implementation, curriculum review \\
\hline Accountant & Disbursement of funds to the sites \\
\hline M\&E manager/IT team & $\begin{array}{l}\text { Management of data sent by the sites (Kids Club and clinical records), } \\
\text { routine reporting }\end{array}$ \\
\hline $\begin{array}{l}\text { Nurse coordinators } \\
\text { ( } 26 \text { in number, majority } \\
\text { of whom are female) }\end{array}$ & $\begin{array}{l}\text { Scheduling, planning, and budgeting of the club meetings; notification } \\
\text { to children/caregivers of upcoming meetings; facilitation of the } \\
\text { meetings; documentation and reporting; ad hoc meetings with } \\
\text { caregivers; supervision of field agents employed by the project }\end{array}$ \\
\hline Field agents & $\begin{array}{l}\text { Logistical support for club meetings, notification to children/caregivers } \\
\text { of upcoming meetings, follow-up/home visits with children and } \\
\text { caregivers (some are employed directly by the hospital) }\end{array}$ \\
\hline
\end{tabular}

As noted above, the Kids Club program was fully integrated within the overall BEST project (and now Project Impact Youth); thus, all Kids Club staff have other major responsibilities within the project. In particular, at the site level, nurse coordinators and field agents wear many hats.

We not only have [the] kids club, we have community clubs, we train teachers, we have other parallel activities, all that is [about] educating, sensitizing, HIV prevention ... it is the education department that takes care of it.

\section{-Program manager B, Caris Foundation}

We have other work with the project. We visit the sites, collect information about [the children] and then record the numbers at the office. We also take data for the children newly screened positive so we can do follow-ups in terms of diet, adherence to medicines, home visits. We send agents to visit them in case of disease so Caris can help them. We meet with the site managers to follow up on children who miss appointments. We 
do the tracking for them so they can go to the appointments on time; we monitor the viral load and give the list to the sites so that they can schedule.

-Nurse coordinator, Group A

Not only do we organize clubs, but we also do follow-ups for [the children]. If they are sick, we take them to the hospital, they receive drugs according to their case. [We pay for] expensive drugs that parents cannot afford. We help children who have weight loss problems, skin problems. Once the child goes to the club and we notice that something is wrong, we take care to visit; it to better understand the problem. We help him find dry rations to help him physically so that he is healthy. If the child has mental problems and cannot stay with his family, we look for foster homes or orphanages to place him. If his case requires a psychologist, we act accordingly.

-Nurse coordinator, Group B

Nurse coordinators maintain close contact with the health facility staff. Some formally coordinate and communicate club meeting and clinic appointment schedules.

2 The [hospital] staff know when the clubs meet. They are invited to participate in the club if they have time; some of the staff will actually facilitate the sessions. Then we often provide food for the clinic staff at the same time. Some of the staff will choose to take the children to the clinical appointment at the same time as the club.

-Program manager D, Caris Foundation

66

[Health facility staff] know all the children who are at the club. When the children have problems, we communicate with them and they help us [help the children]. If parents need a medicine, they help us find them at a better price. They know the program of the clubs well, and follow [up] with the parents for the appointments and medications. So we work together and have a close communication.

-Nurse coordinator, Group B

66

We share the plan of the clubs each month with the hospital. We send an email to the hospital, we share the dates of the club meetings, the hospital posts the schedule. Then each time the children/[caregivers] come to hospital appointment, they see the calendar.

-Nurse coordinator, Group C

At most sites, the nurse coordinators work in teams. For example, at Nos Petit Frères et Soeurs, which serves a large number of children, a team of two coordinators and an agent manage six clubs. In other smaller locations, coordinators manage sites at several different hospitals. 
Normally, each team is composed of two nurses; there are teams that have a nurse

and a social worker. In my team, there are two nurses, so we help each other and co-animate the club; we share the spots. If a subject has several activities, for example games, songs, demonstration, everyone does a part or we do them together.

-Nurse coordinator, Group B

Nurse coordinators convene annually at headquarters for refresher training and a curriculum update. Routine supportive supervision visits are also provided, although the frequency reportedly varied across sites.

We have a supervision [visit] every three months ... evaluation of the club, how we conduct the session, and the next day when we arrive at the office, they share the results where we can see the strengths and the weaknesses, and that can help us improve. This visit is not announced; this is a surprise visit.

-Nurse coordinator, Group C

For the club, there is not really a team from Port-au-Prince that comes to supervise.

They supervise remotely through the documents [we submit] where we record the information ... the education officer doesn't routinely come to the province office. If I remember well, it's been more than two years since he came.

-Nurse coordinator, Group D

The project maintains two primary databases for project planning, monitoring, and reporting: Club Schedule and HIV Haiti.

We have a worksheet named Club Schedule, where we put the schedule of the club

so that the responsible persons can know that on such a date there is such a club in such an area. After the club, in the club schedule, we register the presence, the reason of the cancellation of a club, the name of the children and what they have received, and the topics presented.

-Nurse coordinator, Group A

We take information from iSanté to update our HIV Haiti system. For instance, if a child had a follow-up visit today, when the nurse goes to the hospital to follow up on a child, she will check on iSanté to see if there was an update done for that child. Once the update is done on iSanté, she records the information and then this information goes to HIV Haiti.

-Program manager C, Caris Foundation

\section{Enrollment, progression, and graduation processes}

The BEST project identified sites eligible to participate in the Kids Club program through its tracking of HIV-positive children at the sites it supported. Once an agreement with the hospital 
was established, site managers shared the list of eligible children and youth, and a group meeting was held with caregivers. Home visits were made to those who did not attend the group meetings.

We ask the hospital for authorization, the hospital invites the parents/caregivers, and then we have a big meeting. We present the project and they sign a consent form to say that they agree to send their children to the clubs.

-Program manager A, Caris Foundation

2 The hospital informs us of eligible children by giving us a list of names, then we visit the children at their parents' house to ask for the parents' approval for the participation of children in the club. At this moment, we explain to them what the club is, its advantages, its importance.

-Nurse coordinator, Group B

Enrollment took place on a rolling basis. To enroll new children into existing clubs, multiple avenues were used, including meeting the child and caregivers at their hospital visits, calling the caregivers, and home visits.

When our nurse coordinators visit the hospitals, they ask whether or not there are any more children who are eligible for the club enrollment. This is something we are always checking to make sure that no one is being missed.

-Program manager E, Caris Foundation

The club was introduced to caregivers as an educational opportunity for the children, an opportunity for the children to interact with others, and support for ART adherence.

When I first heard about the club, they told me they were looking for children to train to attend the club. When they go to the club, they can see some other children, some friends.

-Caregiver of child in 13- to 17-year-old club, Hôpital Sacré Coeur de Milot

66 They invited us to a meeting, they told what will they do with the child; after, if we want, we will sign. We saw it was not a bad thing, we decided to enroll them because when they talked about the club, they said the kids would come and they will talk to them. They say they will have a friend, so they know how to live, how to take the pills.

-Caregiver of child in 13- to 17-year-old club, Hôpital Saint Damien Nos Petits Freres et Soeurs

During an orientation session at their first club meeting, the club was presented to the children as a place where they could discuss their problems and learn. The children's HIV status was not discussed. 
[The club] is explained to them as a safe place for them to meet and talk about any

worries they have or any concerns or problems that they have...a place for them to learn new topics that they may not have heard about to help prepare them and help them make safe decisions.

-Program manager E, Caris Foundation

66 The first session of the curriculum is an introductory and welcome session-what we are going to do, what we are doing. But we don't introduce the topic [of their HIV status]. It is rather the parents [who do that].

-Program manager A, Caris Foundation

A protocol reportedly exists for transitioning children into the next higher club type as they age and includes an assessment of their knowledge and readiness. However, managers noted that it has not been implemented consistently.

According to the protocol, we are to administer a questionnaire annually to assess children's knowledge... [but] we tend to keep them a little longer.

-Program manager A, Caris Foundation

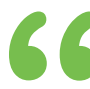

There is no set rhythm for transitioning children because ... the child must complete one level to pass to another, taking into account curriculums and themes. For example, a child of 9-12 must complete Year 1, Year 2, and Year 3. If, for example, Year 2 is not fully completed, the child will not be able to attend .... Year 3. All curricula and themes must be seen.

-Program manager B, Caris Foundation

66 We evaluate each child individually to assess whether they are ready to move up to the next age group. -Program manager E, Caris Foundation

Managers and nurse coordinators disagreed about the existence of criteria and a process for graduation from the program; some understood that completion of a two-year training to become a peer educator was needed for those age 18 and older to qualify for graduation.

2 We have exit [graduation] strategies for other parts of our program, but not for the clubs ... because I think just as much as the children enjoy being in a club, they should benefit. We would like the child to be able to benefit until he is no longer a child.

-Program manager A, Caris Foundation

66 To [graduate] the club, the children must have 18 years or more. At this level, they receive training for two years to become peer educators and they graduate and then leave. But until now, we don't have children who have graduated.

-Nurse coordinator, Group A 
When they reach age 18 or older, they receive another training, a peer educator training ... selected kids who completed this training have become what we call field supervisors ... they are employed by Caris and supervise "community clubs."

-Nurse coordinator, Group C

\section{Club interventions}

The core of the Kids Club program is the club meeting. Each club meets on a monthly basis for approximately two to three hours. Meetings typically are held on site at the health facility or a nearby location. Most age groups at a site meet at different times, although some meet concurrently in different or adjacent locations.

We facilitate these clubs together in the same space. I have 13- to 17-year-olds; she has 9- to 12-year-olds. We present the topics for each group separately and then we do the other activities together.

-Nurse coordinator, Group A

The format is similar across club locations and age groups. Managers, nurse coordinators, caregivers, and Kids Club participants were all in agreement that during the club meetings, children receive education on a health or social topic, encouragement to take their medication, an opportunity to interact with one another, psychosocial support, a hot meal, and hygiene kits-and that Caris Foundation provides funds for transportation to and from the club meetings. Medication reminders are given at the end of all club sessions.

There is a procedure. It's designed this way: they start with a prayer, a group activity,

then after that they cover the material and there are certain activities that they do together that are like team building ... at the end, there is the distribution of hot meals, transport fees, hygiene kits. Children have time to interact a little.

-Program manager A, Caris Foundation

The services that they give in the club, first of all they show them how to live and take the medications, they give them food, transportation fees, hygiene kits.

-Caregiver of child in 9- to 12-year-old club, Hôpital Sacré Coeur de Milot

We usually play, we usually speak, they give us information.

-Caregiver of child in 9- to 12-year-old club, Hôpital Bernard Mevs

At a club meeting, we share ideas ... the [nurse coordinator] teaches us, shares beautiful ideas with us. Then they give us food, they give us money, and they send us home.

-Child in 13- to 17-year-old club, Grace Children's Hospital 
We are encouraged to take our medications in order not to die.

-Child in 9- to 12-year-old club, Hôpital Immaculée Conception des Cayes

At least one meeting a year is devoted to an outing. Some meetings include entertainment, and a party is held each December that also includes the families of the children.

They go to places we do not know, they go to a local garden, they take them to different places, and when they get back home, they say: mom, we went to the lake or to the beach where I have never been before.

-Caregiver of child in 13- to 17-year-old club, Hôpital Sacré Coeur de Milot

Sometimes the artists come to play for them, especially Mikaben; the child can't sleep, and when he gets up, he says "Mom, Mikaben came to play for us, danced for us, sang for us."

-Caregiver of child in 13- to 17-year-old club, Hôpital Saint Damien Nos Petits Freres et Soeurs

66 [They like] the party... because during party season we can say that there are people who don't have time to come to the clubs, but when there is a party you will see them because they not only receive gifts, but the children like the atmosphere ... they'll come to dance.

-Nurse coordinator, Group C

We go to a fun day yearly; they have a Christmas party for us in December.

-Child in 9- to 12-year-old club, Hôpital Sacré Coeur de Milot

66 They go out with us, for recreation, to enjoy ourselves, to have some pleasure; we always go out, they always do this with us, go and have fun with other young people, take part in activities, and that's always good for us, allowing our minds to develop.

-Youth in 18-year-old + club, Hôpital Immaculée Conception des Cayes

Some nurse coordinators meet one on one with the children at the end of the club meeting to address individual concerns or anonymously solicit concerns from children and take further action.

After the club, we give a little time to the children who have some concerns. We meet them, listen to them, and give some advice according to the level of the problems. Sometimes when the children come to the club, we ask them if they have complaints and we give them some sheets of paper to write them [down]. When we go to the office, we 
put them in the complaint box and we do follow up with the responsible parties as fast as possible for the ones that are urgent.

-Nurse coordinator, Group A

Although the Kids Club program does not include formal sessions with the caregivers of the enrolled children, caregivers may interact with the club nurse coordinators (and agents) on a oneto-one basis, primarily concerning the child's medication adherence. Caregivers noted that they learn about what goes on during club meetings from children's reports to them-and, for some clubs, sitting outside the meeting and hearing what takes place.

When we come to the club, they tell us how to give the medications to the children and how to talk to them, the way to give the medicines to them; we do not have to force them, or talk hard to them, and we have to sit down to talk to them. They usually tell us about that.

-Caregiver of child in 13- to 17-year-old club, Grace Children's Hospital

66 It's with them they speak, not with us. If we do not ask them questions [about] what they were talking [about] to them, we will never know what they were saying to them.

-Caregiver of child in 9- to 12-year-old club, Hôpital Saint Damien Nos Petits Freres et Soeurs

When we sit there, we hear when they talk inside with the children. When [the children] come back home, they explain to us about what they discussed.

-Caregiver of child in 9- to 12-year-old club, Hôpital Bernard Mevs

\section{Curriculum}

Program managers reported that a structured, three-year curriculum guides the educational component of the meetings. Based generally on other best practice HIV/AIDS curricula, and interactive in its format, it was developed by Caris Foundation specifically for the Haitian context at the start of the Kids Club. The content of the curriculum is tailored to the three club age groups. The curriculum includes monthly topics presented in sequential order. New topics have been introduced to reflect changing conditions, as relevant.

We have developed three kinds of curricula, one for 9-12, one for 13-17, one for 18 and older. The topics are similar but treated differently. The curriculum is for three years.

-Program manager B, Caris Foundation

The curriculum was developed initially by [Caris Foundation staff] with some Haitian teachers and public health professionals, focusing on HIV and sexually transmitted 
diseases topics. We also looked at the "It's all ONE curriculum"5 for some other sexual health topics.

-Program manager D, Caris Foundation

All of the curriculum is written here for the Haitian context, in French for the providers, but also in Creole. We kind of adapted it to local issues; [for example,] when cholera came, adding cholera and hand washing.

-Program manager D, Caris Foundation

[The nurse coordinator] gives all the information to the children about the topic, the children ask questions, the nurse coordinator asks questions, there is an exchange, there is an interaction.

-Program manager B, Caris Foundation

Documentation on curriculum topics obtained from Caris Foundation suggests that although the curriculum for the 9- to 12-year-old club is three years long, the 13- to 17-year-old club curriculum covers four years, and the 18-year-old + curriculum covers two years (see Annex B for the list of curriculum topics). Nine to 15 sessions are presented each year, depending on the year and age group. The topic of HIV is not included in the curriculum for the 9- to 12-year-old group because some of the children are unaware of their HIV status. The topic of gender-based violence (GBV) also is not included in the curriculum for the youngest age group.

66 It's from [age] 13-17 that HIV is introduced because not all the little ones know their status. There are some who know if they are infected, but there are some who do not know, so we treat HIV from [age] 13-17, but at the same time when we are going to treat these topics, we make sure that everyone knows their status. We work with the psychology department that assists with disclosure, so once all the children are aware, we do the theme ... If it's only one child who does not know his status, we do not do this subject. We will do another subject [instead], called "risks and danger." We added GBV for older children; it was also done for [ages] 13-17; the little ones don't have gender-based violence.

-Program manager B, Caris Foundation

66 The hospital starts the disclosure process at ages 12-13 years; by ages 13-14, the disclosure is complete. So in the 13- to 17-year-old club, we talk clearly, but first we ensure that disclosure for all children is done. For the 9-to 12-year-old club, we speak in general [about drug adherence], like about someone who has the flu [or] who has fever and is taking a medicine; or like your mother has hypertension and has to take hypertension medicines.

-Nurse coordinator, Group C

${ }^{5}$ Nicole Haberland, Deborah Rogow, Ofelia Aguilar, et al. 2009. It's All One Curriculum: Guidelines and Activities for a Unified Approach to Sexuality, Gender, HIV, and Human Rights Education. Population Council. 
Although not a formal component of the curriculum, some English language is taught as part of the lesson.

There is an English lesson that we do for the kids, where there are some key words in the session, we teach them the English equivalent for their personal knowledge.

-Nurse coordinator, Group C

Children and youth referred to many of the curriculum topics when asked about what was taught during the club sessions. Among those most commonly cited were medication adherence, health and hygiene, sex education and contraception, peer pressure, respect for others, self-esteem, and human rights.

They tell us to watch over our health, take the medicines to not get ill ... when you are taking the medicine to not throw it away.

-Child in 9- to 12-year-old club, Hôpital Saint Damien Nos Petits Freres et Soeurs

They talk with us about HIV disease and self-esteem. They share about tuberculosis.

They tell us about violence and early pregnancy.

-Child in 13- to 17-year-old club, Grace Children's Hospital

They say how to take care of our bodies, especially when you have menstruation; not to have sex.

-Child in 9- to 12-year-old club, Hôpital Sacré Coeur de Milot

They taught us how to respect ourselves, how to respect other people. We must respect our parents. How to respect other people's opinion. And also other things like sexual education, as well; they talk about different types of contraceptive methods. They even taught us abstinence [smiling]. Also, they told us that we might not be able to wait; they gave us different methods to use.

-Child in 13- to 17-year-old club, Hôpital Immaculée Conception des Cayes

Sometimes they discuss topics that really touch my heart. They told us not to have friends who drink alcohol or smoke; me, I have these kinds of friends who do that a lot.

-Child in 13- to 17-year club, Hôpital Sacré Coeur de Milot Last Saturday, the topic was on how to behave in society, how to claim our rights. 
Caregivers reported awareness of the range of topics that children are taught. The most commonly cited were ARV medication adherence and self-esteem.

Not everyone can know everything they say to the child. But sometimes, when I ask questions of the child, [he says] they are asking him if he takes his medication on time and how to take his medication.

-Caregiver of child in 13- to 17-year-old club, Hôpital Saint Damien Nos Petits Freres et Soeurs

She tells me that she wants to become a nurse. But there was someone who told her that [because of] the illness she could not become a nurse. But when she is in the club, they say to her, it is not true. She told me also that she couldn't go on any trip because of the illness. When she comes to the club, they say it is not true; there is nothing you cannot do because [of] your illness.

-Caregiver of child in 13- to 17-year-old club, Hôpital Immaculée Conception des Cayes

They show them how to live, they tell them that they have the same value as everyone; they don't need to ... worry because of the disease.

-Caregiver of child in 9- to 12-year-old club, Hôpital Sacré Coeur de Milot

\section{HIV status disclosure}

Disclosure to a child of her/his HIV status is not addressed directly through the clubs. Rather, support for disclosure is provided by the health facility and/or support from the psychologists employed by Caris Foundation. Additionally, in 2016, Caris Foundation initiated a separate, formal disclosure program that works with healthcare providers, caregivers, and children. In at least some of the 13- to 17-year-old clubs, most of the children have become aware of their status.

When it is time [for] the children to know their status in order to take their

responsibilities, we ask for [the] help of some psychologist at the level of the central office or we go to the hospital to find a psychologist and plan an appointment with the children and their parents.

-Nurse coordinator, Group A

We started [the disclosure program] mainly because it came to our attention that some of the children were not made aware of their status, either [because] the parents did not feel comfortable doing so or the hospital didn't feel comfortable doing so. So [the children] were attending the clubs and still receiving all the health messaging, but they didn't know that they were living with HIV.

-Program manager E, Caris Foundation

In the 13- [to] 17-year club, about 90 percent of the children know their status ... it is the hospital that takes care of that.

-Nurse coordinator, Group D 


\section{Engagement with caregivers}

There is no formal program with the parents as part of the Kids Club program. However, the nurse coordinator and agent stay in contact with the caregivers. Reportedly, the agents have closer contact with the caregivers through their home visits. One group of nurse coordinators also described convening a meeting of children and caregivers to receive viral load results.

2 If the children are not adhering to their medications, the nurse coordinator can see that when the child comes to the club. They are going to talk to the parents to know what happened when children have skin problems or lose weight. If there are some medical follow-ups to do, they will ensure that the children go to the hospital; they ask for the medical test. So there is a close relationship between the parent/caregiver and the nurse coordinator or the agent.

-Program manager B, Caris Foundation

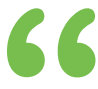

There are some parents who come to the club with the children; we [the nurse coordinators] have contact with them. Despite ... that, we contact them only if there are problems. We take the opportunity to talk to them about adherence to the club, the hospital, and the medications, or if they have some needs.

-Nurse coordinator, Group A

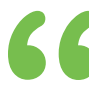

The person who has more contact with the parents is the agents. Sometimes we organize meetings for the 13- [to] 17-year club to learn their viral load results. We ask them to come with their parents so we can motivate them more about the adherence of the children. We talk to them and encourage them to have more control in the way the children take their medications.

-Nurse coordinator, Group D

\section{Observation of the clubs}

Observation of the club meetings at the five study locations confirmed information obtained from the FGDs, interviews, and project documentation, but also provided additional contextual information, including observed similarities and differences across the clubs, as follows:

- Physical environment. Clubs at four of the five sites were held in a room or semi-enclosed space at the health facility; at one site, the meetings were held in a church courtyard. Most spaces were not private. At the church location, other people routinely entered the space, including neighborhood children attracted by the games.

- Schedule and timing. Clubs were held both in the morning and afternoon. All clubs were delayed in starting due to the late arrival of some participants. They ranged in length from one to one and a half hours. At one site, three clubs met sequentially, and the meal was served after the last club meeting; thus, the earlier clubs had to wait until the last club ended to receive their meal. At another site, all three age group clubs met concurrently in same space.

- Child and youth participants. The sessions had an average of 15 participants, with a minimum of nine participants and a maximum of 21 . More girls were present than boys. In all groups, there were some participants who were older than the designated age group of the club. All children were clean and appropriately dressed. 
- Nurse coordinators. All of the clubs were facilitated by female nurse coordinators, who were generally assisted by one or more female and male agents. The nurse coordinators led the activities, and the agents helped with logistics-for example, distributing hygiene kits, water purifying products, hot meals, and drinks, and keeping the space clean. In some locations, agents escorted some children to the club meetings. At other sites, agents also accompanied children to their clinical appointments after the club meetings. The nurses were very comfortable with the children and knew their names. They conducted the sessions with ease, coordinating their activities smoothly to switch from one nurse coordinator to the other. They all used lesson plans to lead the club session.

- Activities. Generally, all the clubs followed the same format and sequence, as follows:

- Informal and formal welcome of the participants

- Opening prayer

- Rapid health assessment (i.e., who took their medicines, missed doses, went to medical appointments, missed the appointment, has a fever or cough, etc.)

- Recap of the topic discussed at the last meeting

- Announcement of the topic of the current meeting, with questions to the group about what they know about the topic

- Teaching of some English words related to the topic of the day

- Delivery of the lesson using different techniques, such as a formal presentation, practical exercises, games, and video projections

- Recapitulation of the lesson key points

- Distribution of transportation fees, hygiene kits, and water-purifying products

- Provision of hot meals with soft drinks

- Announcement of the next meeting date

- Closing prayer

- Participant interaction. Overall, participants showed focused attention during the presentation of the topics by the nurse coordinators. They participated in activities conducted by the nurse coordinators and responded to the questions during the lesson. They were engaged in the games, appeared relaxed, and laughed a lot. Within each group, some children were more engaged than others. There was no noticeable difference between the age groups regarding engagement and participation. Although no time was formally dedicated to allow children to interact with each other, they took advantage of pauses, such as during distribution of health kits and the meal, to speak with one another.

\section{Assessment of program implementation}

Participants in all three club age groups expressed the importance of the Kids Club program to them personally. They acknowledged their appreciation for the education and activities during the club meetings, and the way they are treated.

We spend good times when we meet, we receive good direction. [The club meetings are] well prepared and we have nice parties, everything always goes well.

-Child in 9- to 12-year-old club, Hôpital Immaculée Conception des Cayes 
I am always happy about the activity they do in the club. They always do parties, they

organized journeys for us, they show us all that we want in the club. I am always happy with what they do in the club.

-Child in 13- to 17-year-old club, Hôpital Sacré Coeur de Milot

What I like the most is the way they treat the children in the club. If a child doesn't understand something, they explain it several times.

-Child in 13- to 17-year-old club, Grace Children's Hospital

66

What I see as most important is the advice of the [coordinators] ... how do we manage our disease in order to be healthy, and a set of things that we should not do and precautions to take.

-Youth in 18-year-old + club, Hôpital Immaculée Conception des Cayes

Caregivers and the nurse coordinators confirmed the children's statements.

2 I have a boy who likes everything that he does at the club; if there was one thing that he did not like he would not be so interested to attend.

-Caregiver of child in 9- to 12-year-old club, Hôpital Bernard Mevs

66 The children are very interested in the activities. They are always saying that Caris is a mother, Caris is a father.

-Nurse coordinator, Group C

They are happy when they announce the excursion and can even choose the area where they want to go. They like when they organize parties for them. They like most those things and others.

-Caregiver of child in 9- to 12-year-old club, Hôpital Sacré Coeur de Milot

Favorite topics in the curriculum varied among Kids Club participants, but often included those addressing puberty, healthcare and HIV, self-esteem, and peer pressure. Nurse coordinators concurred. Caregivers expressed their gratitude to the clubs for providing sex education and educating children on HIV transmission and condoms.

I like when they tell me about my body. I can know how to protect my body.

-Child in 9- to 12-year-old club, Hôpital Sacré Coeur de Milot 
In all the topics they discussed with us, I like self-esteem the most (Participant 1). I

like peer pressure the most (Participant 2). For me, it's [the] HIV topic that I like the most (Participant 3).

-Children in 13- to 17-year-old club, Grace Children's Hospital

All subjects have an impact on them, but self-esteem, puberty-[the children] like them a lot.

-Child in 13- to 17-year-old club, Hôpital Saint Damien Nos Petits Freres et Soeurs

66 They also like the "peer pressure" topic. They learn to not let friends influence them, like pressuring them to do something; they learn what is good, what is bad ... If they have a friend and they see that this friend wants to lead them in the wrong direction ... they should not let this friend influence them, but it is they who should influence this friend.

-Nurse coordinator, Group C

Caregivers reported their own appreciation of the clubs, most frequently for the training provided, including sex education, and medication adherence support. Universally, they expressed their gratitude for the respect and care provided by the nurse coordinators. They also noted the importance of the social aspects of the club.

What I like most about the way the club works [is] the education and training that is given.

-Caregiver of child in 9- to 12-year-old club, Hôpital Immaculée Conception des Cayes

66

Training they make for the kids on how to manage their health helps the child in

everything. What I like [is that] they tell the kids about everything.

-Caregiver of child in 13- to 17-year-old club, Hôpital Saint Damien Nos Petits Freres et Soeurs

Some parents have been afraid to tell their children about sex, about condoms. The club also taught them they can get pregnant having sex without protection, they will be infected ... they speak to the children in the club and, most importantly, since the child is 13 or 14, she can get pregnant. It is the most important thing they tell them, when she lets a little boy do her so and so, she can get pregnant. Also, ... she knows she can get the virus.

-Caregiver of child in 13- to 17-year-old club, Hôpital Saint Damien Nos Petits Freres et Soeurs 
I go to the club with my sister ... when my sister arrives at the club, she is appreciated by others, it makes me very happy. They talk to her .... [the nurse coordinator] proves to me that she loves her, she talks to her once my sister arrives, she lets my sister hold her phone as if she were her daughter.

-Caregiver of child in 9- to 12-year-old club, Hôpital Immaculée Conception des Cayes

2 What I like most is when they do training for them, they talk to them about everything

in life, about illness, anything that can happen if they do not take their drugs, all the good that happens when they take their drugs. They talk to them as if they were their children; they take care of them as if they came out of their womb.

-Caregiver of child in 9- to 12-year-old club, Hôpital Immaculée Conception des Cayes

66 During the club, they are happy, they can make friends; when the time arrives for them to meet, they hug. This is a place where they meet their friends, and it is a friend with whom they can talk [about] everything, a friend who is facing the same situation.

-Nurse coordinator, Group C

When asked if there are aspects of the club that they would like to see changed to make it better, children and youth often said they were happy with the clubs as they are now. Many caregivers also agreed, suggesting that Caris Foundation should be the ones to recommend changes, if needed.

2 I can say that I love everything in the club, there aren't things that I don't like.

Everything pleases me.

-Child in 13- to 17-year-old club, Hôpital Sacré Coeur de Milot

62 I would not change anything because everything is done well.

-Child in 9- to 12-year-old club, Hôpital Saint Damien Nos Petits Freres et Soeurs

2 I do not see anything to change in the club. They [Caris Foundation] know necessity, they know need, they have to choose to know what to do for the kids.

-Caregiver of child in 9- to 12-year-old club, Hôpital Saint Damien Nos Petits Freres et Soeurs

Others recommended improvements ranging from changing the venue and schedule to expanding activities to improving the services currently provided. Illustrative recommendations are presented in Table 7. 
Table 7 Recommended changes to improve the Kids Club program, from club participants, caregivers, and program staff

\section{Recommendation Quotation}

Meet more frequently "I would meet twice a month. The reason why I would do it twice a month is to give more explanation to the children.

-Child in 13- to 17-year-old club, Hôpital Saint Damien Nos Petits Freres et Soeurs

Change the meeting location

"I would like the site [venue] to change. The truth is, when I come, it's just to relax. It is true that subjects are important [but] we could be in a more comfortable space where we can run, play, all that."

-Child in 13- to 17-year-old club, Hôpital Immaculée Conception des Cayes

"I would like the club to change location, to stop coming to the hospital, rent a place ... any location, a private one."

-Child in 13- to 17-year-old club, Grace Children's Hospital

"For the club to be better, if they can have their own space to organize the club. The fact that they don't have a location dedicated to the club, the date varies every month. They must submit a schedule and ask for the space, and [those] responsible choose the date that fits to them. That explains why there is variation in the date."

-Caregiver of child in 9- to 12-year-old club, Hôpital Sacré Coeur de Milot

Get together with other clubs

Foster opportunities to showcase talent
"I would like to visit other clubs because I would like to meet more people." -Child in 13- to 17-year-old club, Hôpital Immaculée Conception des Cayes

"There are shy talented people [in the club]. It is true that they discussed topics with us just to overcome that. But most of them are still not confident that way. I would like for members of the club to showcase these children's talent. Among us, there are artists who know how to sing, dance; there are people who make sandals, bracelets. There are people who keep their talent [to] themselves. They don't show them to others ... to overcome shyness, they could organize a contest. On a Saturday for example, they [could] do a singing contest and the better singer wins a prize."

-Child in 13- to 17-year-old club, Hôpital Immaculée Conception des Cayes 


\section{Recommendation}

Provide skills training

\section{Quotation}

"Our parents know we are in the club, but we would like to bring more for them. For example, if [the club] could teach us crafts, floral trades, and other things that might be useful tomorrow, the parents would be happy."

-Youth in 18-year-old + club, Hôpital Immaculée Conception des Cayes

"Have some activities for the children, some vocational training to learn, like macramé, making sandals ... crafts are the market leaders, teaching children to do something good for them, it will help their lives tomorrow."

-Caregiver of child in 13- to 17-year-old club, Hôpital Saint Damien Nos Petits Freres et Soeurs

"The 18+ children always ask if the organization could help them learn a manual occupation because some are orphans and don't have anyone who can help them after their high school. Or if they can recruit some people who can help them do manual things like crafts, floral art, cooking. I would like the organization to add some manual occupation."

-Nurse coordinator, Group A

Increase transportation reimbursement

"Regarding the transportation fees, I want them to increase it because there are times the money isn't enough to take us where we are going." -Child in 13- to 17-year-old club, Hôpital Immaculée Conception des Cayes

"The subsidies do not cover the transport costs. My daughter has a foot handicap, she cannot walk. To go to the club, I pay a motorcycle to transport her and I walk for one hour. I would like Caris to make a little more effort for us".

-Caregiver of child in 9- to 12-year-old club, Hôpital Bernard Mevs

Improve the contents of the hygiene kit*

We do not use deodorants because they are not good quality; they give sores under your arm. There is also toothpaste that is given that is not good quality; when children use it, there are small abscesses that appear in their mouths.

-Caregiver of child in 9- to 12-year-old club, Hôpital Immaculée Conception des Cayes

"What they have to change for us is the toothpaste and the deodorant. Because it creates sores in children's teeth. The deodorant makes them have [a] bad odor. They cannot use it.

-Caregiver of child in 13- to 17-year-old club, Grace Children's Hospital

"Some nurse coordinators acknowledged awareness of dissatisfaction with some contents of the kits and reported they had made substitutions. In the distribution of the kits and products, we sometimes ask the opinion of the beneficiaries; they can have some products they don't like and ask us to change them. We change them for them because it is they who will use them."

-Nurse coordinator, Group D 
Nurse coordinators all shared that they encountered few challenges in implementing the clubs, but several did offer recommendations for improvement related to instructional materials and aids, and psychosocial support.

I don't see too much room of improvement. Everyone has capacity. We can adjust things when necessary.

-Nurse coordinator, Group B

66

The recommendation that I have for the club to better serve the children, if the

children could have at their disposal the materials that we use ... because when they are reading, they will memorize more things that they will use for the community, their home, some general topics, help their parents, the community, and replicate the information.

-Nurse coordinator, Group D

At headquarters, there are psychologists and social workers who work with the parents; I would like the same in the province also-to have that in the clubs.

-Nurse coordinator, Group D

Program managers also reflected on improvements they would like to make to the Kids Club program and the broader package of services. These thoughts included better capacity to target and support children who are not virally suppressed, scaling out the disclosure intervention, making better use of the data they collect, and taking steps to ensure sustainability of the Kids Club program.

I think if we can identify kids, adolescents that are not virally suppressed because of potential adherence problems ... we need to have a focus on them, the subset of kids who are not doing so great, to think about ways that we could support them better.

-Program manager D

66 ... to have the disclosure program as a standardized thing in each of the clubs, that's something we really want to focus on.

-Program manager $\mathrm{E}$

I would like the results [of the pre- and post-questionnaires] to be shared with the sites, the coordinators, the children. Before they were at this level, they did not know this or that information, but at the end of the club, they have another level ... it would encourage them much more, that they learned something. 
[Encourage] the health facility to offer the clubs as an integral part of the care package ... "empower" them to implement the clubs. Then, if the project is no longer there, staff at the site will have the "know how" and mechanism to continue them.

-Program manager A

\section{Program outcomes}

\section{Club attendance}

About three-quarters of those ever enrolled in a club (78 percent) participated (or were exposed to the club) for at least one year-that is, they attended a minimum of two club meetings and the date of their last club meeting was at least 12 months later than the date of their first meeting. ${ }^{6}$ As shown in Table 8, the one-year minimum participation rate varied by department, year of enrollment, participant's age, and club type ( $p<0.001)$, but not by sex of the child. Grand'Anse and Sud departments showed the highest rates ( 85 percent and 84 percent, respectively), whereas Nippes showed the lowest rate (47 percent). Nearly all of the 2014 and 2015 cohorts (99 percent and 95 percent, respectively) remained in the club for at least a year, compared to 70 percent and 87 percent among the 2016 and 2017 cohorts. Only those in the 2018 cohort who were enrolled in January could qualify for at least 12 months of participation; thus, as would be expected, this cohort had the lowest minimum participation rate ( 7 percent). Children ages 8-12 years and those in the youngest club type were less likely than older children and those in the older club types to have participated for at least 12 months. Closer analysis showed that at least part of the age and club differences may be explained by the fact that the participants in the youngest age group made up more than half of the 2018 cohort, and thus did not have the opportunity to participate for at least 12 months.

Some 78 percent $(1,038 / 1,330)$ of all children ever enrolled in a club were active during the 2018 calendar year-that is, they attended at least one club that year; 2018 attendance varied by department, year of enrollment, participant's age, and club type $(p<0.001)$, but not by sex of the child. Children in clubs in Nord department were about half as likely to have attended in 2018 compared to those in Artibonite, Centre, and Nord-Est, where all children attended at least one club. By definition, all children in the 2018 cohort attended at least one meeting. The highest rate among the earlier cohorts was 93 percent, which was among the 2017 cohort; those enrolled in 2015 and 2016 were least likely to have attended a meeting in 2018-69 percent and 67 percent, respectively. Attendance in 2018 was negatively associated with age as well as club type. For example, 93 percent of ever-enrolled children ages 8-12 years compared to 61 percent of those ages 18 years and up attended a club in 2018.

Caris Foundation routinely reports on highly active club members, defined as those who have not missed more than three club visits within a 12-month time period. Highly active participation in 2018 was examined among the subset of 1,179 children and youth enrolled in the Kids Club program as of December 2017. As shown in Table 8, slightly more than half (55 percent) had participated actively in 2018. Highly active participation varied by all measured characteristics

${ }^{6}$ All club enrollees were included in the attendance analyses unless otherwise noted, including those whose participation ended at any point due to severe illness or death. 
Table 8 Club attendance

\begin{tabular}{|c|c|c|c|}
\hline $\begin{array}{l}\text { Club participant } \\
\text { characteristics }\end{array}$ & $\begin{array}{c}\text { Participated for at least } \\
12 \text { months }{ }^{a} \\
\%(n)\end{array}$ & $\begin{array}{c}\text { Active in } 2018^{\mathrm{b}} \\
\%(\mathrm{n})\end{array}$ & $\begin{array}{l}\text { Highly active in } \\
2018^{\circ} \\
\%(n)\end{array}$ \\
\hline \multicolumn{4}{|l|}{ Department } \\
\hline Artibonite & $53(18 / 34)^{* * *}$ & $100(34 / 34)^{* * *}$ & $90(18 / 20)^{* \star *}$ \\
\hline Centre & $80(32 / 40)$ & $100(40 / 40)$ & $88(28 / 32)$ \\
\hline Grand'Anse & $85(49 / 58)$ & $78(45 / 58)$ & $59(31 / 53)$ \\
\hline Nippes & $47(23 / 49)$ & $69(34 / 49)$ & $45(17 / 38)$ \\
\hline Nord & $68(137 / 203)$ & $58(117 / 203)$ & $42(79 / 189)$ \\
\hline Nord-Est & $71(17 / 24)$ & $100(24 / 24)$ & $83(10 / 12)$ \\
\hline Nord-Ouest & $82(86 / 105)$ & $76(80 / 105)$ & $58(51 / 88)$ \\
\hline Ouest & $82(474 / 581)$ & $80(462 / 581)$ & $51(269 / 532)$ \\
\hline Sud & $84(161 / 191)$ & $87(166 / 191)$ & $66(112 / 171)$ \\
\hline Sud-Est & $78(35 / 45)$ & $80(36 / 45)$ & $71(31 / 44)$ \\
\hline \multicolumn{4}{|c|}{ Year of club enrollment } \\
\hline 2014 & $99(147 / 148)^{* * *}$ & $78(116 / 148)^{* * *}$ & $66(97 / 148)^{* * *}$ \\
\hline 2015 & $95(400 / 422)$ & $69(293 / 422)$ & $48(202 / 422)$ \\
\hline 2016 & $70(236 / 336)$ & $67(224 / 336)$ & $45(151 / 336)$ \\
\hline 2017 & $87(238 / 273)$ & $93(254 / 273)$ & $72(196 / 273)$ \\
\hline 2018 & $7(11 / 151) 4$ & $100(151 / 151)$ & - \\
\hline \multicolumn{4}{|l|}{ Sex } \\
\hline Female & $77(539 / 703)$ & $77(541 / 703)$ & $53(334 / 627)$ \\
\hline Male & $79(493 / 703)$ & $79(497 / 627)$ & $57(312 / 552)$ \\
\hline \multicolumn{4}{|c|}{ Age at club enrollment } \\
\hline $8-12$ years & $69(321 / 472)^{* * *}$ & $82(386 / 472)^{* * *}$ & $61(235 / 383)^{* * *}$ \\
\hline $13-17$ years & $84(485 / 579)$ & $81(468 / 579)$ & $58(307 / 531)$ \\
\hline $18-29$ years & $81(226 / 279)$ & $66(184 / 279)$ & $39(104 / 265)$ \\
\hline \multicolumn{4}{|c|}{ Last club type attended } \\
\hline 9- to 12-year-old & $71(406 / 575)^{* * *}$ & $83(478 / 575)^{* * *}$ & $63(299 / 476)^{* * *}$ \\
\hline 13- to 17 -year-old & $82(460 / 563)$ & $76(429 / 563)$ & $53(275 / 523)$ \\
\hline 18-year-old + & $87(166 / 192)$ & $68(131 / 192)$ & $40(72 / 180)$ \\
\hline Total & $78(1,032 / 1,330)$ & $78(1,038 / 1,330)$ & $55(646 / 1,179)$ \\
\hline
\end{tabular}

Source: Caris Foundation monitoring database.

${ }^{a}$ Difference between last club meeting date and first club meeting date $\geq 12$ months.

${ }^{\mathrm{b}}$ Attended at least one club meeting in 2018.

'Among those enrolled through December 2017, did not miss more than three club meetings from January-December 2018.

$*, * *, * * *$ Differences among the groups are statistically significant at $p<0.05, p<0.01$, and $p<0.001$, respectively.

except sex, following patterns similar to those for active participation, as measured by at least one visit in 2018. 
As shown in Table 9, children and adolescents enrolled throughout the five-year project period attended 16.2 club meetings on average, with a range of 1 to 51 meetings. As expected, the mean number of meetings attended was higher among those who had been enrolled longer, although the decrease across enrollment cohorts was not linear. For example, the 2016 and 2017 cohorts both averaged about 12 meetings.
Table 9 Number of club meetings attended

\begin{tabular}{|lrrrrrr|}
\hline $\begin{array}{l}\text { Year of } \\
\text { enrollment }\end{array}$ & $n$ & Mean & S.E. & Min & Max & Median \\
2014 & 148 & 33.5 & 1.003 & 7 & 51 & 38 \\
2015 & 422 & 20.0 & .477 & 1 & 39 & 22 \\
2016 & 336 & 12.7 & .448 & 1 & 33 & 14 \\
2017 & 273 & 11.6 & .299 & 1 & 24 & 12 \\
2018 & 151 & 4.8 & .218 & 1 & 10 & 5 \\
Total & 1,330 & 16.2 & .313 & 1 & 51 & 14 \\
\hline
\end{tabular}

Club attendance was reported to be a priority among the children participating in the FGDs. They shared that they rarely missed a club meeting and were unhappy if unable to attend because they missed their friends and the topics discussed. They also expressed a desire to continue to attend the clubs for a long time to come. Caregivers, too, emphasized their commitment to club attendance.

Because I'm attached to the club, I come every time.

-Child in 9- to 12-year-old club, Hôpital Immaculée Conception des Cayes

I would like to stay in the club for always because I love the club a lot.

-Child in 13- to 17-year-old club, Hôpital Sacré Coeur de Milot

When there are activities and you can't come because of troubles in the country or lack of money to pay the transportation fees, we feel sad. When your friend calls you and asks why you didn't come-and explains to you what.... was done, we feel sad.

-Child in 13- to 17-year-old club, Hôpital Saint Damien Nos Petits Freres et Soeurs

I feel comfortable in the club, I have a lot of good times, I want to stay for as long as it exists.

$$
\text { -Youth in 18-year-old + club, Hôpital Sacré Coeur de Milot }
$$

When the time comes, steal or borrow, the child must come to the club "laughter". Even if you are doing the laundry, you have to leave it and go to the club.

-Caregiver of child in 9- to 12-year-old club, Hôpital Sacré Coeur de Milot

For the most part, there was broad agreement among program managers and implementers, caregivers, and children that street violence, political unrest, lack of resources (primarily for 
transportation), school schedule conflicts (especially during exam periods), and heavy road traffic contributed to children missing club meetings. Other reasons included summer holidays and illness. Schedule conflicts with employment and college attendance were reported to contribute to irregular attendance among some youth in the 18 years and up clubs.

The difficulties are when...I hear shots and people run from one side to the other. At this moment, it is difficult to find a bus to reach the meeting on time.

-Child in 9- to 12-year-old club, Hôpital Immaculée Conception des Cayes

66 The difficulty that we find is the transportation fee because there are some of us who don't have [a] mother and father; if we don't have money to pay [a] vehicle or motorcycle, it's a difficulty to come to the club.

-Youth in 18-year-old + club, Hôpital Sacré Coeur de Milot

66 The only problem [with attendance] is when you go to pick up the child when he is attending a school course, when he is in examination period.... This may cause him to miss a day and not come. But if there is no school, there is no problem.

-Child in 9- to 12-year-old club, Hôpital Immaculée Conception des Cayes

36 Sometimes I am sick [and can't come to a club meeting].

-Child in 9- to 12-year-old club, Hôpital Saint Damien Nos Petits Freres et Soeurs

66 The children who miss the meetings more are some in the 18-year-old + groups because some of them work, and some of them have finished secondary school and go to the college.

-Nurse coordinator, Group D

Program managers cited several reasons for children no longer participating in clubs, including death of the child, geographic relocation of the child or household, pregnancy among adolescent girls, and parental decisions. Efforts are made to bring those who have dropped out back into the clubs.

2 There may be a child who changes address or, unfortunately, if the child dies, but otherwise [we do not see many children dropping out of the clubs].

-Program manager B, Caris Foundation

A reason that causes children [to stop attending the club meeting], for the girls, is they get pregnant. Sometimes they are moved to live farther away or their parents leave the department.

-Nurse coordinator, Group A 
66

When we do come across children who are dropping out, then we visit them to find out why that is and if there's any way we can help bring them back in [we try it] because we also don't want them abandoning care at the hospital. So, we generally have a way of speaking to the children to try to encourage them to come back, we speak to their parents. It's often...sometimes it's a parental decision. It's quite rare that the child decides he doesn't want to come. We haven't really encountered that.

-Program manager E, Caris Foundation

\section{Knowledge, learning, and behavior change}

Children and youth of all ages reported that they have gained a great deal of knowledge through their participation in the clubs. Older participants were more likely than younger ones to say that this learning has changed their lives. However, caregivers often described positive behavioral changes among younger children as well.

What I learn is in relation to the subjects that they teach. Now, when I put them into practice, I have different behavior from the way I was before. It is in relation to the subjects (they teach) that my life has changed.

-Youth in 18-year-old + club, Hôpital Immaculée Conception des Cayes

I learn a lot from the club, there are many topics that they discuss with us. These topics make us grow ... because school doesn't teach everything.

-Youth in 18-year-old + club, Hôpital Sacré Coeur de Milot

66

When children come to the club, they receive good training. They learn how to talk to their friends, neighbors, [and parents] ... When the neighbors say that you have a good child who has good behavior ... when they congratulate your child, it is very important to us.

-Caregiver of child in 9- to 12-year-old club, Hôpital Immaculée Conception des Cayes

Some club participants described specific ways they have changed their attitudes and behavior, including their outlook on life and choice of peer groups,

Before, I was really careless, I did not take anything seriously except school. When I started to understand and think about everything I learned in the club, I realized that I must take everything seriously.

-Child in 13- to 17-year-old club, Grace Children's Hospital

There are things that they talked about, like alcohol. I used to have friends who were forcing me to drink alcohol, I took my distance from them, I do it less now and I have changed.

-Child in 13- to 17-year-old club, Hôpital Sacré Coeur de Milot 


\section{Psychosocial development and well-being}

Children, youth, caregivers, and nurse coordinators all spoke of the contributions of the Kids Clubs in helping participants overcome shyness, improve self-esteem, and instill happiness and hope in their lives.

I could say they taught us how to value ourselves ... like some children behave as if they don't exist. They stay in [the] corner. But they taught us how to stand up for ourselves, to be proud of ourselves. So that we know we are human, that we are living.

-Child in 13- to 17-year-old club, Hôpital Immaculée Conception des Cayes

They taught us how to live comfortably in society, how to be a responsible man, and then to live well, better.

-Child in 13- to 17-year-old club, Grace Children's Hospital

There was a way the child did not develop before. But they give them training, take them to other areas; they meet little friends ... see new images ... [that's] what develops their minds.

-Caregiver of child in 9- to 12-year-old club, Hôpital Bernard Mevs

The children are happy, they are no longer in sadness.

-Caregiver of child in 9- to 12-year-old club, Hôpital Bernard Mevs

It helps them, it gives them the desire to live, they are not discouraged when they see that others care about them. It encourages them, they are not abandoned ... it means that the child is not a lost cause.

-Caregiver of child in 9- to 12-year-old club, Hôpital Immaculée Conception des Cayes

I have a child who was very shy and I always encouraged her to attend the club, where there are some club activities. I told her it would help her to get developed instead of staying home. She was afraid and she told me there are many children and they would look down on her. I told her "No, they are all like you" and she did not have to be afraid. It encouraged her and thanks to that, she is no longer timid.

-Caregiver of child in 13- to 17-year-old club, Hôpital Sacré Coeur de Milot

There are some children who were shy before coming to the club, but we can see that their behavior has changed-for example, through changes in their answers from the pre- and post-questionnaires we use to evaluate the curriculum.

-Nurse coordinator, Group D 


\section{Living positively with HIV}

Those who are aware they are living with HIV talked about how their participation in a club helped them better understand the disease, how to stay healthy, and how to live positively.

The club taught us how we got the disease and what measures to take.

-Child in 13- to 17-year-old club, Grace Children's Hospital

[The Club] helps us a lot to stay healthy, to better our health condition.

-Youth in 18-year-old + club, Hôpital Immaculée Conception des Cayes

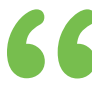

The advice they give us through the subjects about this disease, not just telling us

about its treatment, but the way they describe it, shows us how to behave facing this disease. I found it very important because when one is living with this kind of sickness it may lead to suicide. This [advice] helps me personally to move on, it also allows me to believe in my future, to believe that I can do a lot of things, and that the disease that I have cannot stop me.

-Youth in 18-year-old + club, Hôpital Immaculée Conception des Cayes

\section{Retention in care}

Nurse coordinators noted that the clubs help participants maintain follow-up appointments with their clinical care.

3 It helps them to be part of the appointments, they come more often to the hospital.
-Nurse coordinator, Group B

\section{ART adherence}

Children and youth from all clubs cited the value of learning to take their medications. Older youth referred to giving and receiving these benefits through peer support within the clubs in addition to receiving the information from the nurse coordinators.

3 When they treat the topic [of taking medication] with me, I feel well.

-Child in 9- to 12-year-old club, Hôpital Sacré Coeur de Milot

Before the topics they discussed with us regarding the medication, I used to not take them, but now I take them, it changed me a lot.

-Child in 13- to 17-year-old club, Hôpital Sacré Coeur de Milot 
When my grandmother gave me the medicines, I threw them away, I didn't drink them. When I came here, the nurses talked to me; after that, I saw how the club works, and I followed the information, I began to improve and drink the medications.

-Youth in 18-year-old + club, Hôpital Sacré Coeur de Milot

66

When we get into the club, we share that [we are living with HIV], and when we

notice some teens who don't feel well, sometimes they are too weak, we can talk to them and when they explain to us, we can encourage them to take medicine and talk to them.

-Youth in 18-year-old + club, Hôpital Immaculée Conception des Cayes

Caregivers and nurse coordinators also described how participation in the Kids Club has led to improvements in children taking their medication.

After getting into the club, he is starting to talk with some little friends, now she is beginning to drink the medication well.

-Caregiver of child in 9- to 12-year-old club, Hôpital Saint Damien Nos Petits Freres et Soeurs

2 The club helps to manage the health of children; sometimes children are repugnant to drugs, but when they participate in the club, they even encourage us to give them the drugs because the nurses tell them to take them every day.

-Caregiver of child in 9- to 12-year-old club, Hôpital Bernard Mevs

2 The fact that they attend the club regularly and we talk to them about adherencesometimes it is they who remind their parents to give them medications and to take them to the hospital.

-Nurse coordinator, Group A

Clinical data on self-reported ARV adherence were available within the past three years for 62 percent $(833 / 1,330)$ of all children and youth ever enrolled in a Kids Club. Results showed that among them, 77 percent reported taking 100 percent of their doses in the month before their last visit, and 73 percent reported no missed doses in the preceding four days. ${ }^{7}$ As shown in Table 10 , both adherence indicators were found to differ by department $(p<0.001)$, although in some cases, sample sizes were small and estimates should be interpreted with caution. Adherence also differed by club enrollment cohort; for example, the 2015 cohort had the lowest percentage of adherers for both measures, at $p<0.05$. Differences by sex and among age group and club type were small and not statistically significant. No difference in adherence was found according to length of time participating in the program, but both adherence measures were associated with total number of club meetings attended-that is, 84 percent of those attending at least 24 club

${ }^{7}$ Both questions regarding ARV adherence are asked during routine clinic visits. 
meetings reported 100 percent of doses taken in the past month, and 79 percent reported no missed doses in the past four days, compared to 75 percent and 71 percent $(p<0.01$ and $p<0.05$, respectively) of those attending fewer meetings. Active and highly active participation in 2018 were both associated with the two adherence measures; that is, 80 percent who were active in a club in 2018 reported 100 percent adherence, and 75 percent reported no missed doses, compared to 67 percent and 66 percent ( $p<0.001$ and $p<0.01$, respectively) among those who were inactive in 2018.

\section{Viral load suppression}

Approximately 70 percent of the 1,130 children and youth ever enrolled in a Kids Club had at least one viral load test within the past three years with results available on the iSanté central server. Among them, 64 percent were virally suppressed (i.e., had a viral load result of less than 1,000 copies $/ \mathrm{ml}$ ) at the time of their most recent test. As shown in Table 11, viral load suppression varied considerably among departments, ranging from 17 percent in Artibonite to 76 percent in Ouest, $p<0.001$. Although sample sizes for some departments were small and should be interpreted with caution, closer examination of Ouest department, which had the largest number of Kids Club participants (and the highest percentage who were virally suppressed) suggests differences exist between sites as well. For example, 82 percent $(197 / 239)$ of children at Hôpital Saint Damien Nos Petits Freres et Soeurs were virally suppressed compared to 63 percent $(82 / 130)$ at the other combined six sites within Ouest department. Differences in viral load suppression among enrollment cohorts, age groups, and club types, and by sex, were small and not statistically significant. Although a larger percentage of those who had participated in the program for at least 24 months were virally suppressed compared to those who participated for shorter periods, the differences were not statistically significant. However, children and youth who attended at least 24 club meetings were more likely to be virally suppressed than those attending fewer meetings, at 69 percent vs. 62 percent, respectively, $p<0.05$. Also, a higher percentage were virally suppressed among those active compared to inactive in 2018, 66 percent and 57 percent, respectively, $p<0.05$. A similar difference was found for those highly active compared to those not highly active, but the difference was not statistically significant. 
Table 10 ARV adherence, by club participant characteristics

\begin{tabular}{|c|c|c|}
\hline Club participant characteristics & $\begin{array}{l}\text { Reported } 100 \% \text { doses } \\
\text { taken in past month } \\
\qquad \%(n / N)\end{array}$ & $\begin{array}{c}\text { Reported no missed } \\
\text { doses in past } 4 \text { days }^{a} \\
\%(n / N)\end{array}$ \\
\hline \multicolumn{3}{|l|}{ Department } \\
\hline Artibonite & $20(1 / 5)^{* * *}$ & $50(1 / 2)^{* * *}$ \\
\hline Centre & $97(38 / 39)$ & $97(38 / 39)$ \\
\hline Grand'Anse & $98(52 / 53)$ & $100(53 / 53)$ \\
\hline Nippes & $74(32 / 43)$ & $81(29 / 36)$ \\
\hline Nord & $63(111 / 175)$ & $60(106 / 176)$ \\
\hline Nord-Est & $92(12 / 13)$ & $92(12 / 13)$ \\
\hline Nord-Ouest & $82(55 / 67)$ & $91(41 / 45)$ \\
\hline Ouest & $74(214 / 289)$ & $68(198 / 293)$ \\
\hline Sud & $88(89 / 101)$ & 74 (100/135) \\
\hline Sud-Est & $84(26 / 31)$ & $76(31 / 41)$ \\
\hline \multicolumn{3}{|l|}{ Year of club enrollment } \\
\hline 2014 & $85(69 / 81)^{*}$ & $79(75 / 95)^{*}$ \\
\hline 2015 & $72(169 / 236)$ & $66(159 / 241)$ \\
\hline 2016 & $74(180 / 242)$ & $73(178 / 243)$ \\
\hline 2017 & $82(135 / 164)$ & 75 (131/175) \\
\hline 2018 & $83(77 / 93)$ & $83(66 / 79)$ \\
\hline \multicolumn{3}{|l|}{ Sex } \\
\hline Female & 76 (321/424) & 73 (312/429) \\
\hline Male & $79(309 / 392)$ & $74(297 / 404)$ \\
\hline \multicolumn{3}{|l|}{ Age at club enrollment } \\
\hline $8-12$ years & $78(234 / 300)$ & 72 (226/315) \\
\hline $13-17$ years & $74(256 / 344)$ & $72(252 / 349)$ \\
\hline $18-29$ years & 81 (140/172) & 78 (131/169) \\
\hline \multicolumn{3}{|l|}{ Club type at last visit } \\
\hline 9- to 12-year-old & $79(284 / 360)$ & $73(276 / 378)$ \\
\hline 13- to 17-year-old & $74(255 / 346)$ & $72(248 / 343)$ \\
\hline 18-year-old and above & $83(91 / 110)$ & $76(85 / 112)$ \\
\hline \multicolumn{3}{|l|}{ Length of club participation } \\
\hline$<12$ months & $74(141 / 191)$ & $76(133 / 176)$ \\
\hline $12-24$ months & $78(171 / 218)$ & $73(167 / 228)$ \\
\hline $24+$ months & $78(318 / 407)$ & $72(309 / 429)$ \\
\hline \multicolumn{3}{|c|}{ Total number of club meetings attended } \\
\hline$<24$ & $75(467 / 622)^{\star \star}$ & $71(444 / 623)^{*}$ \\
\hline $24+$ & $84(163 / 194)$ & $79(165 / 210)$ \\
\hline \multicolumn{3}{|l|}{ Active in a club in $2018^{b}$} \\
\hline Yes & $80(510 / 637)^{* * *}$ & $75(490 / 653)^{* *}$ \\
\hline No & $67(120 / 179)$ & $66(119 / 180)$ \\
\hline \multicolumn{3}{|l|}{ Highly active in a club in $2018^{c}$} \\
\hline Yes & $81(327 / 406)^{* *}$ & $75(324 / 433)^{*}$ \\
\hline No & $71(226 / 317)$ & $68(219 / 321)$ \\
\hline Total & $77(630 / 816)$ & $73(609 / 833)$ \\
\hline
\end{tabular}

${ }^{a}$ At most recent clinical visit that occurred within the three-year period (1 September 2016-31 August 2019).

${ }^{\mathrm{b}}$ Attended at least one club meeting in 2018.

'Among those enrolled before January 2018, did not miss more than three club meetings from January to December 2018.

${ }^{*, * *, * * *}$ Differences among the groups are statistically significant at $p<0.05, p<0.01$, and $p<0.001$, respectively. 
Table 11 Viral load suppression, by club participant characteristics

\begin{tabular}{|c|c|}
\hline Club participant characteristics & $\begin{array}{c}\text { Virally suppressed }^{a} \\
\%(n / N)\end{array}$ \\
\hline \multicolumn{2}{|l|}{ Department } \\
\hline Artibonite & $17(1 / 6)^{* * *}$ \\
\hline Centre & $41(15 / 37)$ \\
\hline Grand'Anse & $56(25 / 45)$ \\
\hline Nippes & $54(23 / 43)$ \\
\hline Nord & $51(86 / 170)$ \\
\hline Nord-Est & $56(5 / 9)$ \\
\hline Nord-Ouest & $60(37 / 62)$ \\
\hline Ouest & 76 (279/369) \\
\hline Sud & 69 (107/155) \\
\hline Sud-Est & $56(22 / 39)$ \\
\hline \multicolumn{2}{|l|}{ Year of club enrollment } \\
\hline 2014 & $68(67 / 99)$ \\
\hline 2015 & $68(196 / 290)$ \\
\hline 2016 & $59(156 / 265)$ \\
\hline 2017 & $63(117 / 186)$ \\
\hline 2018 & $67(64 / 95)$ \\
\hline \multicolumn{2}{|l|}{ Sex } \\
\hline Female & $65(294 / 455)$ \\
\hline Male & $65(306 / 480)$ \\
\hline \multicolumn{2}{|l|}{ Current age } \\
\hline $8-12$ years & $66(235 / 359)$ \\
\hline $13-17$ years & $63(251 / 398)$ \\
\hline $18-29$ years & $64(114 / 178)$ \\
\hline \multicolumn{2}{|l|}{ Current club type } \\
\hline 9- to 12-year-old & $67(291 / 436)$ \\
\hline 13- to 17-year-old & $61(228 / 379)$ \\
\hline 18-year-old + & $68(81 / 120)$ \\
\hline \multicolumn{2}{|l|}{ Length of club participation } \\
\hline$<12$ months & $63(130 / 206)$ \\
\hline 12-24 months & $61(135 / 223)$ \\
\hline $24+$ months & $66(335 / 506)$ \\
\hline \multicolumn{2}{|c|}{ Total number of club meetings attended } \\
\hline$<24$ & $62(424 / 680)^{*}$ \\
\hline $24+$ & $69(176 / 255)$ \\
\hline \multicolumn{2}{|l|}{ Active in a club in $2018^{b}$} \\
\hline Yes & $66(498 / 757)^{*}$ \\
\hline No & $57(102 / 178)$ \\
\hline \multicolumn{2}{|l|}{ Highly active in a club in $2018^{c}$} \\
\hline Yes & $66(325 / 496)$ \\
\hline No & $61(211 / 344)$ \\
\hline Total & $64(600 / 935)$ \\
\hline
\end{tabular}

aMost recent viral load test that occurred within the three-year period (1 September 2016-31 August 2019). Of note, 95\% of the most recent tests occurred in 2018 and 2019.

${ }^{\mathrm{b}}$ Attended at least one club meeting in 2018.

'Among those enrolled before January 2018, did not miss more than three club meetings from January to December 2018.

${ }^{*, * * *}$ Differences among the groups are statistically significant at $p<0.05$ and $p<0.001$, respectively. 
Of note, as shown in Table 12, viral load suppression was highly associated with the two self-reported adherence measures among those club participants who had both viral load and adherence data available.

\section{Program costs}

\section{Resource requirements}

Aligned with the BEST integrated program delivery model, Caris Foundation assessed most Kids Club resource requirements as a percentage of overall project requirements. This allocation applied to all staffing and most operational and supply requirements. Program managers estimated that the Kids Club program required no capital resources, such as furniture, equipment, and vehicles.
Table 12 Association between self-reported adherence and viral load suppression

\begin{tabular}{|lc|}
\hline $\begin{array}{l}\text { Adherence } \text { measures }^{\mathrm{b}} \\
\begin{array}{l}\text { Reported 100\% doses } \\
\text { taken in past month } \\
\text { Yes }\end{array}\end{array}$ & $\begin{array}{c}\text { Virally suppressed } \\
\%(\mathrm{n} / \mathrm{N})\end{array}$ \\
No & $68(401 / 592)^{* * *}$ \\
$\begin{array}{l}\text { Reported no missed } \\
\text { doses in past 4 days } \\
\text { Yes }\end{array}$ & $43(77 / 179)$ \\
No & $67(380 / 569)^{* * *}$ \\
\hline
\end{tabular}

${ }^{a}$ Most recent viral load test that occurred within the three-year period (1 September 2016-31 August 2019).

${ }^{\mathrm{b}}$ At most recent clinical visit that occurred within the three-year period (1 September 2016-31 August 2019).

${ }^{* * *}$ Differences between the groups are statistically significant at $p<0.001$.

BEST did not provide the venues for club meetings directly; rather, they were furnished by the health facility or other partners, such as faith-based organizations, and was not included in the cost analysis. Resource requirements and their allocations, reported for the period 1 January-31 December 2018, are given in Table 13. Program managers reported that the requirements remained unchanged throughout the five-year project period.

Table 13 Resource requirements for the Kids Club program

\begin{tabular}{|lc|}
\hline Resource item & $\begin{array}{c}\text { Percentage allocated for } \\
\text { Kids Club program }\end{array}$ \\
Program manager (1) & 2 \\
Nurse coordinators (26) & 5 \\
Secretary (1) & 1 \\
Bookkeeper (1) & 2 \\
Drivers (20) & 1 \\
Furniture, equipment, and vehicles & 0 \\
Items with recurrent costs & \\
Rent or building maintenance & 0 \\
Vehicle and other transport equipment maintenance & 1 \\
Fuel & 1 \\
Insurance & 0 \\
Telephone & 1 \\
Electricity, water, internet, cleaning services & 0 \\
Office supplies & 1 \\
Training and instructional aids/materials & 0 \\
Transportation for Kids Club participants & 100 \\
Meals for Kids Club & 100 \\
Hygiene kits for Kids Club & 100 \\
\hline
\end{tabular}

Source: Caris Foundation program manager. 


\section{Annual total and per capita costs}

Total annual cost of the Kids Club program was estimated to be US\$113,521. As shown in Table 14 , the two largest cost drivers were Kids Club meals and transportation, which accounted for 32 percent and 31 percent of the cost, respectively, followed by hygiene kits (20 percent), staffing (17 percent), and other recurring costs (0.3 percent). A total of 1,038 children and youth participated in at least one club meeting during the period 1 January-31 December 2018; 699 attended for at least nine of the 12 months of the year. Per capita annual costs calculated using these two estimates of the number of participating children indicated a low estimate of US $\$ 109 /$ participant and a high estimate of US $\$ 162 /$ participant. In 2018, according to the BEST project monitoring database, 23 sites together conducted 55 clubs. Assuming each club held 12 meetings, the average meeting cost was US\$172.

Table 14 Annual Kids Club program costs

\begin{tabular}{|c|c|c|c|c|c|}
\hline Resource item & $\begin{array}{l}\text { Total annual } \\
\text { cost (US\$) }\end{array}$ & $\begin{array}{c}\text { Percentage of } \\
\text { total cost }\end{array}$ & $\begin{array}{r}\text { Per cap } \\
\text { cos } \\
\text { Low }^{a}\end{array}$ & $\begin{array}{l}\text { annual } \\
\text { ge } \\
\text { High }^{b}\end{array}$ & $\begin{array}{c}\text { Average } \\
\text { meeting cost }\end{array}$ \\
\hline Staffing & $\$ 19,181$ & 17 & $\$ 18$ & $\$ 27$ & $\$ 29$ \\
\hline Meals for Kids Club & $\$ 36,565$ & 32 & $\$ 35$ & $\$ 52$ & $\$ 55$ \\
\hline Transportation (total) & $\$ 34,631$ & 31 & $\$ 33$ & $\$ 50$ & $\$ 52$ \\
\hline Hygiene kits for Kids Club & $\$ 22,835$ & 20 & $\$ 22$ & $\$ 33$ & $\$ 35$ \\
\hline Other recurring costs & 309 & 0.3 & $\$ 0$ & $\$ 0$ & $\$ 0$ \\
\hline Total & $\$ 113,521$ & 100 & $\$ 109$ & $\$ 162$ & $\$ 172$ \\
\hline
\end{tabular}

Source: Caris Foundation program managers.

aBased on number of participants attending at least one meeting in 2018 ( $n=1,038)$.

${ }^{\mathrm{b} B a s e d}$ on number of participants who attended at least nine meetings in 2018 ( $\left.n=699\right)$. 


\section{DISCUSSION}

This study provided an in-depth look into the implementation, outcomes, and costs of an established, large-scale psychosocial support intervention for children and youth living with HIV in Haiti. Although the intervention was found to share commonalities with other support group interventions implemented elsewhere in the world, it also differs from many in that it is but one component of a comprehensive package of medical, behavioral, and structural interventions targeting individual children and youth and their support networks. Implementers deliver the package, including the clubs, in a complementary fashion at the facility, community, and household levels. Providing more than psychosocial support, the Kids Club program serves as a nexus of strategies considered essential for improving the lives of highly vulnerable children and youth, and, in some respects, acts as a monitoring and referral system to help ensure this population receives the multitude of services it needs. Commitment to this vision was shared by program managers and implementers alike, and substantiated by caregivers' characterization of the Kids Club program as encompassing medical and social services case management, formal education support, household economic strengthening, and other support. Although the study revealed many benefits of this approach, both in efficiencies of program implementation and reported beneficiary outcomes, the holistic nature of the program model, which was more fully revealed through the study's inquiry, also created a critical limitation for the study-that is, the inability to separate the effects of the Kids Club program from other BEST interventions and clinical care provided by the health facilities to which the program was attached.

Despite this limitation, much was learned to inform future programming in Haiti and other settings. First, the Kids Club program proved scalable. The number of health facilities hosting clubs grew from six to 24 , and enrollment increased nearly tenfold over the five-year period. Whereas nearly half of children served were located in Ouest department (44 percent), followed by Nord (15 percent) and Sud (14 percent), clubs were established in all 10 departments in the country. In 2018, 1,038 children had attended at least one club meeting, representing close to one-third of the estimated number of children in Haiti on ART-with highly active engagement of roughly 20 percent of this population. The program expanded most rapidly in its second year, when nearly one-third of all club members were enrolled. Roughly equal numbers of female and male children were enrolled, and roughly 40 percent are now ages 13-17 years. Most children (81 percent) had initiated HIV care at a health facility at least one year before the start of the Kids Club program in 2014, reflecting most children's acquisition of HIV through vertical transmission and early initiation of clinical monitoring.

Based on observations and information gathered from the in-depth study sites, program fidelity and quality appeared to be high. Interventions were being delivered in a consistent manner across the observed sites, and participants and their caregivers described similar program characteristics, experiences, and satisfaction with the clubs. Standardized meeting planning procedures, curriculum, curriculum schedules, meeting format, and reporting processes were observed to support consistency in Kids Club delivery. Nurse coordinators were highly 
experienced and observed to skillfully deliver the curriculum lessons and facilitate participation among the groups. They also were able to devote attention to individual children and their needs. Children and caregivers frequently commented on and expressed their appreciation for the personalized and compassionate care of the nurse coordinators, remarking on how the coordinators treated the children as their own. Older youth demonstrated trust in the coordinators, often describing them as coaches and advisors.

Some variation across sites was found in the enrollment and graduation processes, however. Lack of clear guidelines on when to transition children to the next club age group, or inconsistency in their implementation, resulted in older children remaining in clubs with a curriculum intended for younger ages. In some cases, this retention may have been merited-for example, when the psychological development of the child was impaired; however, in other cases some children may not be benefiting from more age-appropriate curriculum topics. The fact that some children in the 9- to 12-year-old clubs are aware they are living with HIV, whereas others are unaware, further complicates optimal targeting of the curriculum. Enrollment of children not yet aware of their status sets the Caris Foundation program apart from other models of HIV support groups, which require disclosure as a prerequisite to enrollment (see PEPFAR Solutions Platform 2018). The benefits of reaching children at a young age are promising, but the trade-offs merit further study. As Caris Foundation rolls out the disclosure program in this next project phase, it should consider carefully how it will be integrated with the Kids Club program and what club adaptations may be warranted. Finally, differences in club retention and clinical outcomes were observed across geographic regions and club types, but due to limitations in the study design and data collection scope, it was not possible to determine whether these differences resulted from implementation variations or other factors, such as differing child risk profiles or environmental factors.

A second major finding was that, once enrolled, children and youth tended to stay in the clubs. More than three-quarters of those ever enrolled over the five-year period participated for at least a 12-month period. A similar proportion was active in 2018, and more than half of enrolled children did not miss more than three club meetings that year. On average, participants attended 16 club meetings, with those enrolled early on attending about double the average. Children universally expressed their satisfaction with clubs and their strong desire to attend. Their commitment was reinforced by caregiver and nurse coordinator observations and reflections. Attendance among all age groups was driven both by the desire to learn about the educational topics delivered and the recreation and supportive atmosphere of the clubs. Participants said that they basically "felt better" as the result of attending a club meeting. Participation was not without challenges among this vulnerable population, however, such as transportation constraints (even though the program paid a transportation fee to every participant at each club session), scheduling conflicts with school, and civil unrest and street violence. Although much was learned from speaking with active club participants, little information was available for those no longer active. Program managers spoke anecdotally of geographic relocation and the death of a child as reasons for Kids Club program drop-out, but did not mention routinely accounting for those no longer participating or a definition of program drop-out. 
Evidence suggests a third and very important finding: the Kids Club program has delivered important benefits to its participants, their caregivers, and the clinical staff who care for them. Essential among the benefits was support for ARV medication adherence. Approximately threequarters of club participants reported consistent medication use at their most recent clinic visit. Observed associations of club attendance with adherence measures, assessed through number of club meetings attended and both measures of active participation in 2018, suggest that club engagement may have had a positive effect on adherence. In particular, children and youth, caregivers, and program staff cited many examples of how the clubs have helped participants understand the importance of their medication, which in turn has led to better adherence, better health of the child, and improved clinical management. Nevertheless, due to limitations of the study design, the direction or source of influence of the association between club attendance and adherence cannot be determined conclusively. For instance, children adherent to their medication may be more likely to actively participate in the club program than nonadherent children because they feel better. Also, external factors, such as family care or access to the health facility/club location, may mediate both club participation and adherence.

Of Kids Club members with a recent viral load assessment, 64 percent were virally suppressedconsiderably higher than estimates from other recent studies in Haiti. For example, a study at six Haitian hospitals reported 50 percent virologic suppression among 13-21 year-olds (Jean Louis et al. 2018); PEPFAR reported 40 percent viral load suppression among 15-24 year-olds (PEPFAR 2019); and a recent national cohort analysis of those initiated on ART in 2016 and 2017 reported similar findings for all but one age group-that is, 45 percent virologic suppression among 10-14 year-olds in both cohorts and 50 percent and 87 percent among 15-19 year-olds in the 2016 and 2017 cohorts, respectively (Philippe 2019). Results of our study also showed level of attendance, as measured by number of club meetings attended and at least some participation in 2018 , to be associated with viral load suppression.

Viral load suppression was found to be positively associated with ARV adherence, suggesting that at least some of the association of club attendance and viral suppression was mediated through ARV adherence. Of note, no association between length of club participation and adherence or viral load suppression was observed, suggesting that the number of times a child attends a club may be more important to clinical outcomes than the length of time she remains in the club program. However, geographic variation also was observed, and on closer examination revealed considerable differences in children's virologic suppression across sites.

The Kids Club program reportedly led to other significant outcomes that likely also contributed to improved adherence and virologic suppression, and their broader well-being. Some of the outcomes were learning about their personal health, including puberty and the changes their bodies were undergoing, as well as HIV disease (reportedly popular topics); learning how to handle peer pressure and stigma; and, importantly, overcoming shyness. Many examples cited by children, youth, their caregivers, and program staff pointed to the importance of this learning in club participants' lives and the behavior changes it motivated. The value of the professed joy the clubs also brought to the lives of club participants also cannot be underestimated. These benefits can be attributed directly to the clubs and signal their unique contribution to the overall integrated BEST package of services. 
Finally, analysis of the costs of the program showed that it could be delivered efficiently within the larger package of services at a cost ranging on average from US $\$ 109$ to US $\$ 162$ per club participant per year.

\section{Limitations}

In addition to the limitations noted above, the study had several others that should be considered when interpreting its findings, including the following:

- Qualitative, in-depth analysis was based on a limited number of clubs. Although responses were consistently similar across the sites sampled, they may not be representative of all sites. For example, variations in club member characteristics and outcomes were seen among geographic locations of the clubs, suggesting considerable diversity within the program that the study was not able to capture.

- Clinical data were available for only three-quarters of Kids Club members. Although the subset with clinical data did not appear to differ greatly from the full sample on characteristics that could be assessed, the influence of other factors and the extent of bias they may have introduced in the study is unknown. Further, reasons for the missing clinical data were unknown, which prevented assessment of loss to clinical follow-up. Anecdotal evidence suggested at least some of the missing data were due to upload failures from the health facility to the central server. Additionally, children who transferred across sites could not be tracked because of a lack of unique patient IDs.

- Although internal consistency checks were performed on the quantitative data, other aspects of data quality were unknown, given that all quantitative data were obtained from secondary sources.

- The causal impact of the Kids Club program on observed levels of ART adherence and viral load suppression, and the observed dose-response association, could not be determined given the observational design of the study. The number of children and youth served by other hospitals supported by the BEST project was insufficient to serve as a counterfactual against which to assess the added benefits of the Kids Club program to the BEST package of services. Further, identification of a comparison group from among facilities not supported by BEST was infeasible given data structure and extraction parameters of the central MSPP electronic medical record database. 


\section{CONCLUSIONS AND RECOMMENDATIONS}

\section{CONCLUSIONS}

The Kids Club program, implemented by Caris Foundation under the BEST project from 2014 to 2018, was found to be an essential component of a comprehensive package of services delivered at scale to children and youth living with HIV in Haiti. Viral suppression rates among Kids Club members were above rates reported for children and youth at the national level and in other recent studies conducted in Haiti. A dose-response association was also observed: those with a higher level of club participation were more likely than those who participated less frequently to be virally suppressed. Clinical records also showed high rates of self-reported ART adherence among club members, and self-reported adherence was highly associated with viral suppression. Although limitations of the study design preclude determination of causality within these associations, findings from in-depth qualitative data suggested that the clubs contributed to improved medication adherence and retention in care, which in turn likely contributed to viral suppression. The clubs were also found to have many other reported benefits, including improved health and psychosocial well-being, which likely reinforced ART adherence and were heightened by viral load suppression. Importantly, children and youth attributed changes in their acceptance of living with HIV to the clubs, also citing renewed hope for their futures.

The study's in-depth look at implementation of the Kids Club program suggested that much of its success can be attributed to its close linkages with other mutually reinforcing intervention components as part of a comprehensive package, and that the clubs served to strengthen those linkages. Importantly, they also reportedly facilitated beneficial outcomes of the other services-for example, helping children and youth stay in school and maintain contact with clinical care providers. As a facility-based model, it offers an alternative approach to the more commonly implemented community-based psychosocial support groups and could be explored as a supplement to case management. Finally, program tools and processes, such as its curriculum, training and supportive supervision, and participant monitoring methods, contributed to successful program implementation and could be adapted for scale-up in other settings within and outside of Haiti. 


\section{RECOMMENDATIONS}

Based on the study findings and conclusions, we offer the following recommendations, directed to two audiences.

For Caris Foundation, as it continues to implement the Kids Club program under Project Impact Youth:

- Continue to implement the program in partnership with health facilities; ensure those who become newly eligible are enrolled; and continue to fine-tune operations, starting with improvements recommended by study participants, such as improved venues and more opportunities for skills development.

- Re-examine and update protocols for club progression and ensure consistent implementation across sites to ensure that health messages are targeted appropriately to those who become aware of their HIV status. Realign the timing and content of curriculum topics, as appropriate, to coordinate with the roll-out of the HIV disclosure program.

- Look more closely at the variation in club participant outcomes across sites and determine the sources of variation-including, for example, differences in program delivery and child vulnerabilities, and other factors. Subsequently, develop and implement strategies to scale up best practice and target resources to address gaps, and continuously monitor differences and trends.

- Continue to find ways to promote club members' meeting attendance to ensure their optimal benefits from participation in the program.

For national program leaders and PEPFAR and other global decision-makers:

- Share study findings and foster dialogue on the facility-based model of the Caris Foundation Kids Club program vis-à-vis other psychosocial support models for children and youth living with HIV; promote exchange of tools and learning.

- Continue to motivate and test innovative solutions that support children and youth living with HIV not only to adhere to their medication and maintain viral suppression but also to transition to adulthood and become productive members of society. Support evaluation efforts to better understand pathways of change in order to fine tune programming.

- Support locally led, sustainable approaches that engage the leadership of youth living with HIV to shape their own futures and guide their younger sisters and brothers. 


\section{REFERENCES}

Bain-Brickley, D. et al. 2011. "Interventions to improve adherence to antiretroviral therapy in children with HIV infection (review)," Cochrane Database of Systemic Reviews 12. doi: 10.1002/14651858.CD009513.

Caris Foundation. no date. Description et Rôle des Clubs d'Enfants.

Castro, M., I. González, and J. Pérez. 2015. "Factors related to antiretroviral therapy adherence in children and adolescents with HIV/AIDS in Cuba," MEDICC Review 17(1): 35-40.

Davies, M.A. et al. 2011. "Virologic failure and second-line antiretroviral therapy in children in South Africa--the IeDEA Southern Africa collaboration," Journal of Acquired Immune Deficiency Syndromes 56(3): 270-278. doi: 10.1097/QAI.0b013e3182060610

Fetzer, B. et al. 2011. "Barriers to and facilitators of adherence to pediatric antiretroviral therapy in a subSaharan setting: Insights from a qualitative study," AIDS Patient Care STDS 25(10): 611-621. doi: 10.1089/ apc.2011.0083

Fields, E. et al. 2017. "Qualitative comparison of barriers to antiretroviral medication adherence among perinatally and behaviorally HIV-infected youth," Qualitative Health Research 27(8):1177-1189. doi: 10.1177/1049732317697674

Glass, T. et al. 2015. "Self-reported nonadherence to antiretroviral therapy as a predictor of viral failure and mortality," AIDS 29: 2195-2200. doi: 10.1097/QAD.0000000000000782

lacob, S.A., D.G. lacob, and G. Jugulete. 2017. "Improving the adherence to antiretroviral therapy, a difficult but essential task for a successful HIV treatment-clinical points of view and practical considerations," Frontiers in Pharmacology 8(831). doi:10.3389/fphar.2017.00831.

Jean Louis, F. et al. 2018. "Virologic outcome among patients receiving antiretroviral therapy at five hospitals in Haiti,” PLoS One 13(1): e0192077. doi: 10.1371/journal.pone.0192077.

Murray, K. et al. 2017. "Improving retention in HIV care among adolescents and adults in low- and middle-income countries: A systematic review of the literature," PLoS One 12(9). doi:10.1371/journal.pone.0184879.

PEPFAR. 2019. “Haiti Country Operational Plan (COP) 2019 Strategic Direction Summary.”

PEPFAR Solutions Platform. 2018. "Adherence clubs: increasing retention in care and adherence to life-saving antiretroviral therapy among children and adolescents living with HIV in Tanzania." Retrieved 12 December 2019 (https://www.pepfarsolutions.org/solutions/2018/1/13/ariel-adherence-clubs-increase-retention-and-adherenceamong-children-and-adolescents-living-with-hiv-in-tanzania-fzwjc).

Philippe, R. 2019. “Enquête 2018 rétention sous thérapie antirétrovirale rapport. Draft report." Société d'Étude et de Formation en Information Stratégique, Port-au-Prince.

Programme National de Lutte contre les IST/VIH/Sida (PNLS). 2016. Déclaration d'Engagement sur le VIH2012/2015-2018 (https://mspp.gouv.ht/site/downloads/Declaration\%20d\%20engagement\%20sur\%20le\%20 VIH\%2OPNLS\%2OHaiti\%2OMars\%202016.pdf).

Ridgeway, K. et al. 2018. "Interventions to improve antiretroviral therapy adherence among adolescents in low and middle-income countries: A systematic review of the literature," PLOS ONE 13(1):e0189770. doi: 10.1371/ journal.pone.0189770

Settergren, S. et al. 2018. "Monitoring Outcomes of PEPFAR Orphans and Vulnerable Children Programs in Haiti: Bien Et ak Santé Timoun (BEST) 2018 Survey Findings." Chapel Hill, NC, USA: MEASURE Evaluation, University of North Carolina (https://www.measureevaluation.org/resources/publications/tr-18-287).

Shaw, S., and K. Amico. 2016. "Antiretroviral therapy adherence enhancing interventions for adolescents and young adults 13-24 years of age: A review of the evidence base," Journal of Acquired Immune Deficiency Syndromes 72(4): 387-399.

Smith Fawzi, M.C. et al. 2016. "Mental health and antiretroviral adherence among youth living with HIV in Rwanda," Pediatrics 138(4): e20153235. 
Teasdale et al. 2013. "Adherence and viral suppression among infants and young children initiating protease inhibitor-based antiretroviral therapy," The Pediatric Infectious Disease Journal 32: 489-494. doi: 10.1097/ INF.0b013e31827e84ba

Teasdale, C.A. et al. 2018. "HIV viral suppression and longevity among a cohort of children initiating antiretroviral therapy in Eastern Cape, South Africa," Journal of the International AIDS Society 21(8): e25168. doi: 10.1002/ jia2.25168

UNICEF. 2018. Global and Regional Trends. Retrieved 12 December 2019 (https://data.unicef.org/topic/hivaids/ global-regional-trends/).

Vaz, L. et al. 2010. "Telling children they have HIV: Lessons learned from findings of qualitative study in subSaharan Africa," AIDS Patient Care STDS 24(4):247-56. doi: 10.1089/apc.2009.0217

White, Y. et al. 2008. "Adherence to antiretroviral drug therapy in children with HIV/AIDS in Jamaica," West Indian Medical Journal 57(3):231-237.

World Health Organization (WHO). 2016. Consolidated Guidelines on the Use of Antiretroviral Drugs for Treating and Preventing HIV Infection: Recommendations for a Public Health Approach, Second edition. Retrieved 12 December 2019 (https://apps.who.int/iris/bitstream/handle/10665/208825/9789241549684_eng. pdf;jsessionid=CEB4AA78006A79D61A95F9702DB8E35C?sequence=1). 


\section{APPENDICES}

\section{ANNEX A. BEST PROJECT RESULTS FRAMEWORK}

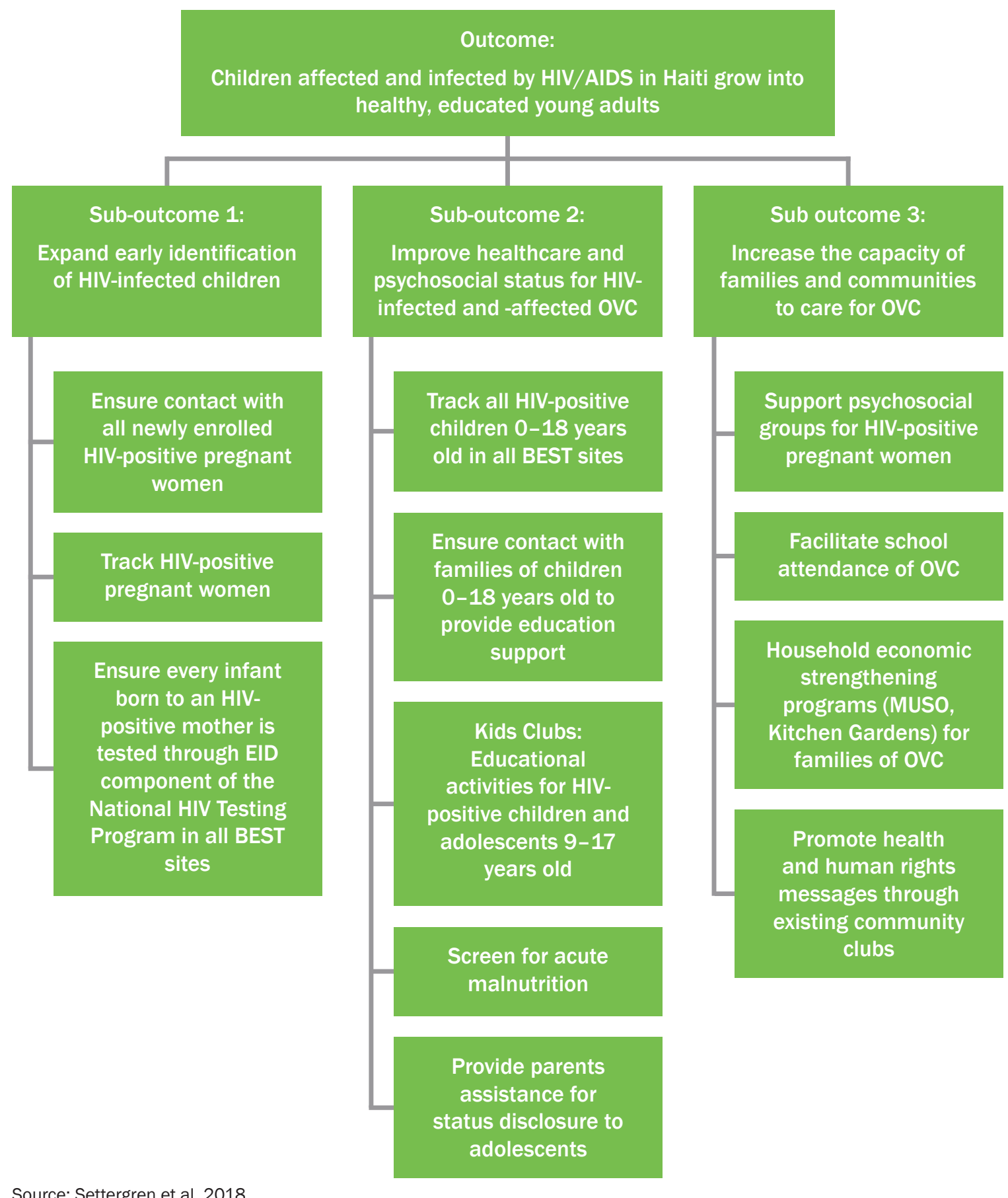




\section{ANNEX B. KIDS CLUB CURRICULUM TOPICS}

\section{9- to I2-year-old club}

Année 1

Séance 1 Introduction

Séance 2 Pré-questionnaire

Séance 3 L'hygiène

Séance 4 La puberté

Séance 5 Bien-être

Séance 6 Importance de la famille

et des amis

Séance 7 La bonne communication

Séance 8 Risques et dangers

Séance 9 L'importance de

l'adhérence aux médicaments

Séance 10 Les droits de l'enfant

Séance 11 Post-questionnaire

\section{3- to |7-year-old club}

Année 1

Séance 1 Introduction

Séance 2 Pré-questionnaire

Séance 3 L'hygiène

Séance 4 Importance de la famille et des amis

Séance 5 Relations romantiques

Séance 6 Santé sexuelle (1)

Séance 7 Santé sexuelle (2)

Séance 8 VIH (Back-up : Risques et dangers)

Séance 9 Comment faire face à la stigmatisation (Back-up : Droits de l'enfant)

Séance 10 Importance de

l'adhérence

Séance 11 Réduire l'anxiété des tests

Séance 12 Post-questionnaire

\section{| 8-year-old + club}

Année 1

Séance 1 Introduction Pair Educateur et son rôle

Séance 2 Hygiène corporelle

Séance 3 Hygiène alimentaire et nutrition

Séance 4 Protection de l'environnement

Séance 5 Décision reproductive

Séance 6 Hygiène femme enceinte et nouveau-né

Séance 7 Conséquences d'être sexuellement active

Séance 8 Infections sexuellement transmissibles

Séance 9 VIH/SIDA -Stigma

Séance 10 Graduation Pair

Educateur 


\section{9- to I2-year-old club}

\section{Année 2}

Séance 1 Soins de premier secours en cas d'urgence

Séance 2 L'éducation et la planification de carrière

Séance 3 Les maladies en Haïti

Séance 4 La puberté

Séance 5 L'amitié et l'amour

Séance 6 Mon corps m'appartient

Séance 7 La pression des pairs

Séance 8 L'harcèlement

Séance 9 Comment faire face à

une perte

Séance 10 Comment maîtriser la colère et le stress

Séance 1 L'estime de soi
Séance 2 La bonne communication
Séance 3 Les relations amicales
Séance 4 La planification du futur
Séance 5 Maltraitance des enfants
Séance 6 Le comportement civique
Séance 7 L'environnement
Séance 8 La nutrition
Séance 9 Le sport

\section{Année 3}

Séance 1 L'estime de so

Séance 3 Les relations amicales

Séance 4 La planification du futur

sén

planification de carrière

Séance 6 Méthodes de

contraception

Séance 7 Grossesse précoce

Séance 8 IST

Séance 9 VIH (Back-up : Les

relations romantiques)

Séance 10 Divulgation (Back-up :

Environnement)

Séance 11 Post-questionnaire

\section{Année 3}

Séance 1 Nutrition

Comportement civique

Séance 3 Pression des pairs

Séance 4 Maltraitance

\section{| 8-year-old + club}

\section{Année 2}

Séance 1 Introduction et PréQuestionnaire GBV

Séance 2 Santé sexuelle

Séance 3 Grossesse précoce

Séance 4 Méthodes de

contraception

Séance 5 Genre

Séance 6 Pouvoir

Séance 7 Violence basée sur le genre

Séance 8 Démarche à suivre

Séance 9 Recours légale

Séance 10 Défense

Séance 11 Estime de soi

Séance 12 Post-Questionnaire GBV 
Project SOAR

Population Council 4301 Connecticut Ave, NW,

Suite 280

Washington, D.C. 20008 USA

Tel: +1 2022379400

Fax: +1 2022378410

Ideas. Evidence. Impact.

projsoar.org 